\title{
MORTALIDADE, POR \\ CÂNCER DE MAMA, DE MULHERES COM IDADE \\ IGUAL E SUPERIOR A 50 ANOS \\ - ESTADO DE SÃO PAULO - 1979 A 1997 -
}

SANDRA DIRCINHA TEIXEIRA DE ARAÚJO

Dissertação apresentada ao Departamento de Saúde Materno-Infantil, da Faculdade de Saúde Pública da Universidade de São Paulo para a obtenção do título de Mestre em Saúde Pública.

Área de concentração: Saúde Materno-Infantil

ORIENTADOR: PROFESSOR ASSOCIADO JOSÉ MENDES ALDRIGHI

São Paulo

2000 
Autorizo, exclusivamente para fins

acadêmicos e científicos , a

reprodução total ou parcial desta

tese, processos fotos copiadores.

São Paulo, dezembro de 2000 
Ao meu pai,

Por tudo que fêz por mim, pelo apoio

e incentivo constante durante minha

trajetória de vida.

Com amor, às minhas queridas irmãs e irmãos Raquel, Marilsa, Cristina, Léia, Raul, Leuces, André e Sérgio e ao meu marido, amigo e companheiro Eli, sem os quais nada teria sentido. 


\section{AGRADECIMENTOS}

Certas pessoas tornaram a elaboração deste trabalho possível e mais completo, e por isso quero lhes agradecer.

- A Deus, por estar presente em todos os momentos da minha vida e me ajudado na elaboração deste trabalho.

- Ao Professor Dr. José Mendes Aldrighi, por ter sido mais do que um orientador, meu agradecimento pela paciência e meu respeito pelas discussões que tanto influênciaram de modo construtivo minha atividade acadêmica.

- À Professora Fumika Peres, pela amizade constante, companheirismo, tolerância e insubstituível colaboração na elaboração deste trabalho.

- Às Professoras. Néia Shor e Keiko, pelo constante apoio, incentivo e amizade, sobretudo, durante o desenvolvimento desta.

- Aos Professores. Marcia Furquim de Almeida e Rui Laurenti, pelas oportunas sugestões.

- Ao Professor José Maria Pacheco de Souza, pelas sensatas sugestões prestadas no exame de qualificação.

- A Professora Ana Cristina Tanaka, pelo incentivo e atenção ao me ajudar em outros trabalhos e pelo apoio importante por ocasião desta qualificação.

- A Professora Sabina Léa Davidson Gotlieb, que despertou em minha pessoa o gosto pela estatística e atenção em me fornecer informações importantes para análise estatística deste trabalho.

- À Francisca, o meu sincero reconhecimento pela acolhida nos momentos difíceis e pela colaboração incansável no levantamento bibliográfico e correção da bibliografia.

- Aos amigos, colegas e funcionários do Departamento Materno-Infantil da FSPUSP, que de alguma forma contribuíram para o presente trabalho.

- A Sérgia, Katiuscia, Miriam e Amália, pela digitação, confecção de tabelas e paciência que me dispensaram no decorrer deste trabalho. 
- Ao Eli e minha família, pelo carinho, apoio e compreensão durante as ausências na elaboração deste trabalho. 


\section{RESUMO}

ARAÚJO SDT. Mortalidade, por Câncer de mama, de mulheres com idade igual e superior a 50 anos - Estado de São Paulo - 1979 A 1997 - São Paulo; 2000. [Dissertação de Mestrado - Faculdade de Saúde Pública da USP].

Este trabalho é um estudo descritivo de série temporal sobre mortalidade por câncer de mama de mulheres com idade igual e superior a 50 anos, no Estado de São Paulo, segundo distribuição na região metropolitana e interior

A partir de informações obtidas no Banco de Dados do Sistema de Informação sobre Mortalidade (SIM) - DATASUS/CENEPI, e de outras fontes subsidiárias, foi estudada sua evolução, por triênios, no período de 1979 a 1997.

No Estado de São Paulo, as estatísticas demonstram que a mortalidade por câncer de mama na população feminina, no segmento etário estudado, apresentou tendência de aumento mais acentuado na região metropolitana (56,57\%). Maiores coeficientes observaram-se no grupo etário igual e acima de 75 anos, cujo coeficiente de mortalidade, no último triênio, revelou crescimento $(47,65 \%)$, sobretudo na região metropolitana, não obstante a expansão de programas de rastreamento e as intervenções eficazes sobre as doenças e as lesões pré-malignas. As taxas de mortalidade específicas por grupos etários, calculadas para os quatro triênios, evidenciam que o risco de morte por câncer de mama não aumentou continuamente com a idade, oscilando entre os grupos etários, em mulheres acima de 50 anos.

Comparam-se os dados brasileiros com os internacionais e tiram-se conclusões, como a que inclui o Brasil no mesmo nível dos países desenvolvidos, quanto às elevadas taxas de mortalidade por esta neoplasia, mas não na consecução de medidas necessárias à prevenção, diagnóstico precoce e controle da doença. Além de comentários sobre os dados estatísticos, é feita uma revisão bibliográfica sobre os fatores de risco da doença. Sugestões são apresentadas, em particular a importância de políticas públicas de saúde voltadas ao grupo feminino na faixa etária acima de 50 anos, dadas as necessidades específicas que apresenta, e que incluem medidas preventivas e de diagnóstico precoce de câncer de mama.

Descritores: Mortalidade da mulher. Câncer de mama. Saúde da mulher 


\section{SUMMARY}

\section{ARAÚJO SDT. Mortality due to breast cancer among women aged 50 years old and more - State of São Paulo - 1979 to 1997 - São Paulo; 2000.}

This research is a descriptive temporal-series study about mortality due to breast cancer among women aged 50 years old and more in the State of São Paulo, according to the distribution in the metropolitan area and the countryside.

From informations obtained at the Banco de Dados do Sistema de Informação sobre Mortalidade (SIM) - DATASUS/CENEPI, and from other subsidiary sources, its evolution was studied, in a triennial fashion, in the period between 1979 and 1997. In the State of São Paulo, the data show that mortality due to breast cancer in the female population, in the age group studied, presented a trend toward a sharper increase in the metropolitan area (56,57\%). Higher coeficients were observed in the 75-years-old or more age group, whose mortality coeficient, in the last triennial, revealed an increase $(47,65 \%)$, most of all in the metropolitan area, in spite of the expansion of screening programs and the efficient interventions on the pre-malignant diseases and lesions. The specific mortality rates for age groups, calculated for the four triennials, demonstrate that the risk of death due to breast cancer didn't raise in a continual fashion with the age, oscillating among the age groups, in women over 50 years old.

The brazilian and the international data are compared, and conclusions are drawn, like that which includes Brazil in the same level as developed countries, as for the high mortality rates due to this neoplasm, but not as for the execution of the necessary measures destinated to prevention, early diagnosis and control of this disease.

Beyond the comments about the statistical data, a bibliographic review is carried on about this disease risk factors.

Suggestions are presented, in particular the importance of public health politics towards the female group in the age group over 50 years old, given the specific needs they present, which include preventive and breast cancer early diagnosis measures. Key Words: Woman mortality. Breast cancer. Woman health. 


\section{ÍNDICE}

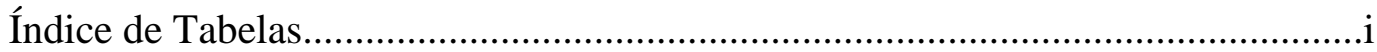

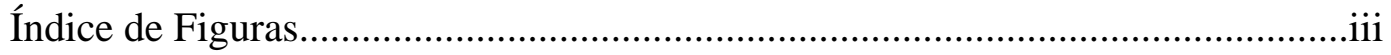

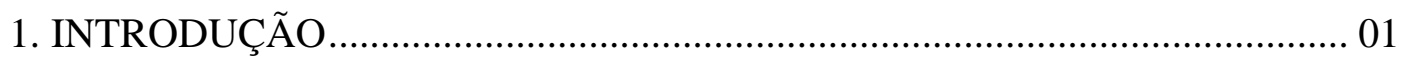

1.1 Magnitude do Câncer de Mama no Mundo e no Brasil............................... 01

1.2 O Câncer de Mama no Contexto da Saúde Pública ...................................... 03

1.3 Fatores Etiopatogênicos e Fatores de Riscos ............................................. 05

1.4 Rastreamento, Detecção e Diagnóstico Precoce .......................................... 10

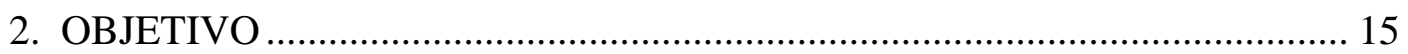

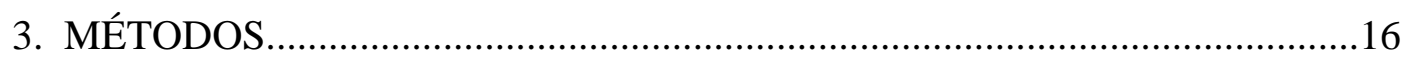

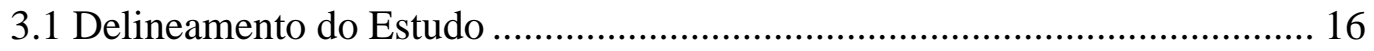

3.2 Caracterização das Áreas Estudadas no Estado de São Paulo ....................... 16

3.3 População de Estudo .............................................................................. 18

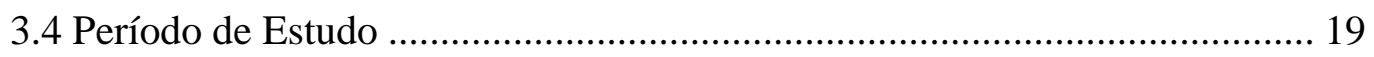

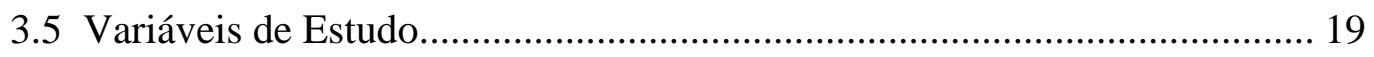

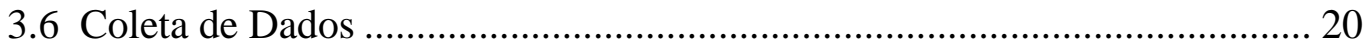

3.7 Apresentação e Análise dos Dados Estatísticos ........................................... 22

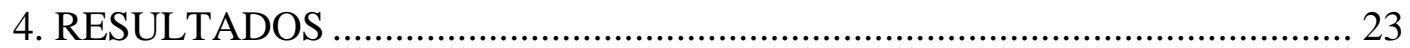

4.1 Resultados Obtidos para o Estado de São Paulo - Região Metropolitana e

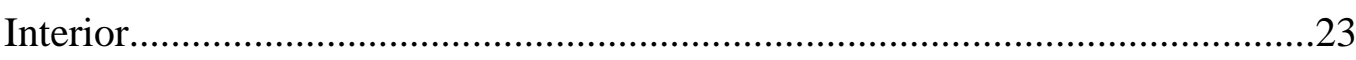

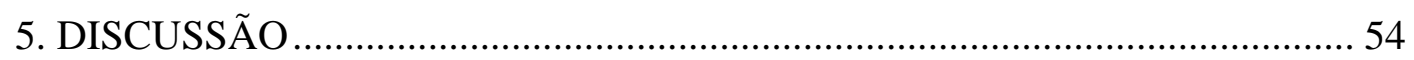

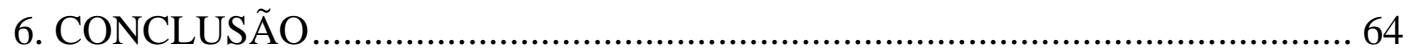

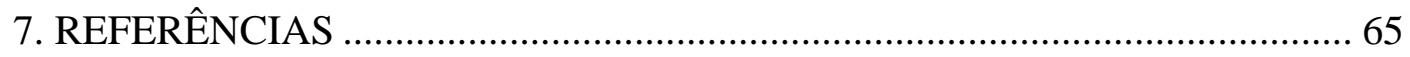




\section{ÍNDICE DE TABELAS E FIGURAS}

Tab. 1. Número e porcentagem de óbitos de câncer de mama, no Estado de São Paulo segundo grupo etário nos triênios 1979-1981, 1984-1986, 1990-1992, 1995 1997. 25

Fig. 1. Número e porcentagem de óbitos de câncer de mama, no Estado de São Paulo segundo grupo etário nos triênios 1979-1982, 1984-1986, 1990-1992, 19951997.

Tab. 2. População feminina, a partir de 50 anos de idade, nos censos de 1980 e 1991 estratificada por faixa etária, no Estado de São Paulo.

Fig. 2. População feminina, a partir de 50 anos de idade, nos censos de 1980 e 1991 estratificada por faixa etária, no Estado de São Paulo.

Tab. 3. Coeficiente (Bruto e padronizado por idade da população feminina com mais de 50 anos de idade no Estado de São Paulo em 1991) de mortalidade por câncer de mama nos triênios 1979-1981, 1984-1986, 1990-1992, 1995-1997

Fig. 3. Coeficiente (Bruto e padronizado por idade da população feminina com mais de 50 anos de idade no Estado de São Paulo em 1991) de mortalidade por câncer de mama nos triênios 1979-1981, 1984-1986, 1990-1992, 1995-1997

Tab. 4. Coeficiente de mortalidade por câncer de mama (por 100.000 mulheres) segundo faixa etária no Estado de São Paulo nos triênios 1979-1981, 1984-1986, 1990-1992, 1995-1997.

Fig. 4. Coeficiente de mortalidade por câncer de mama (por 100.000 mulheres) segundo faixa etária no Estado de São Paulo nos triênios 1979-1981, 1984-1986, 1990-1992, 1995-1997. 
Tab. 5. Distribuição (número e \%) dos óbitos por câncer de mama segundo regiões do Estado de São Paulo, nos triênios 1979-1981, 1984-1986, 1990-1992, 1995 1997.

Fig. 5. Distribuição percentual do total de óbitos por câncer de mama segundo regiões do Estado de São Paulo, nos triênios 1979-1981, 1984-1986, 1990-1992, 1995-1997 .33

Fig. 5a. Número de óbitos por câncer de mama na Região Metropolitana e no Interior de São Paulo, no triênio 1979-1981 .34

Fig. 5b. Número de óbitos por câncer de mama na Região Metropolitana e no Interior de São Paulo, no triênio 1984-1986. .34

Fig. 5c. Número de óbitos por câncer de mama na Região Metropolitana e no Interior de São Paulo, no triênio 1990-1992 .35

Fig. 5d. Número de óbitos por câncer de mama na Região Metropolitana e no Interior de São Paulo, no triênio 1995-1997. 35

Tab. 6. Número de óbitos e coeficiente bruto de mortalidade por câncer de mama (por 100.000 mulheres) nos triênios 1979-1981, 1984-1986, 1990-1992, 1995-1997, e população feminina de 1970, 1980, 1991 e contagem populacional de 1996 ano dos censos, segundo as regiões de estudo no estado de São Paulo. 37

Fig. 6. Coeficiente bruto de mortalidade por câncer de mama (por 100.000 mulheres) nas regiões de estudo no Estado de São Paulo, nos triênios 1979-1981, 1984-1986, 1990-1992 e 1995-1997. 
Tab. 7. Número de óbitos, coeficiente de mortalidade por câncer de mama (por 100.000 mulheres) segundo faixa etária, no triênio 1979-1981, e população feminina de 1980, segundo as regiões de estudo no Estado de São Paulo. .38

Fig. 7. Coeficiente de mortalidade (por 100.000 mulheres) por câncer de mama, segundo faixa etária e regiões de estudo no Estado de São Paulo no triênio 19791981. 38

Tab. 8. Número de óbitos, coeficiente de mortalidade por câncer de mama (por 100.000 mulheres), segundo faixa etária, no triênio 1984-1986, e população feminina de 1980, segundo as regiões de estudo no Estado de São Paulo.

Fig. 8. Coeficiente de mortalidade (por 100.000 mulheres) por câncer de mama, segundo faixa etária e regiões de estudo no Estado de São Paulo no triênio 19841986.

Tab. 9. Número de óbitos, coeficiente de mortalidade por câncer de mama (por 100.000 mulheres), segundo faixa etária no triênio 1990-1992, e população feminina de 1991, segunda as regiões de estudo no Estado de São Paulo. 40

Fig. 9. Coeficiente de mortalidade (por 100.000 mulheres) por câncer de mama segundo faixa e regiões de estudo de Estado de São Paulo no triênio 1990-1992....40

Tab. 10. Número de óbitos, coeficiente de mortalidade por câncer de mama ( por 100.000 mulheres), segundo faixa etária, no triênio 1995-1997, e população feminina da contagem populacional de 1996, segundo as regiões de estudo no Estado de São Paulo .41

Fig. 10. Coeficiente de mortalidade (por 100.000 mulheres) por cancer de mama, segundo faixa etária e regiões de estudo no Estado de São Paulo no triênio 19951997. 
Tab. 11. Coeficiente bruto e padronizado de mortalidade por câncer de mama (por 100.000 mulheres e ajustados por idade pela população mundial), no Estado de São Paulo, nos triênios 1979-1981, 1984-1986, 1990-1992 e 19951997.

Fig. 11. Coeficiente bruto e padronizado de mortalidade por câncer de mama (por 100.000 mulheres e ajustados pela idade pela população mundial) 43

Tab. 12. Coeficiente bruto e padronizado de mortalidade por câncer de mama (por 100.000 mulheres e ajustados por idade pela população mundial 1991), segundo as regiões de estudo no Estado de São Paulo, nos triênios 1979-1981, 1984-1986, 19901992 e 1995-1997. .44

Fig. 12. Coeficiente bruto e padronizado de mortalidade por câncer de mama (por 100.000 mulheres e ajustados por idade pela população mundial), segundo as regiões Estado de São Paulo, nos triênios 1979-1981, 1984-1986, 1990-1992 e 19951997

Tab. 13. Número e porcentagem de óbitos Segundo segundo grupo etário nos triênios 1979-1981, 1984-1986, 1990, 1992 e 1995-1997. .45

Fig. 13. Coeficiente bruto e padronizado de mortalidade por câncer de mama (por 100.000 e ajustados pela idade, pela população feminina do Brasil - Censo 1991), nos triênios 1979-1981, 1984-1986, 1990-1992 e 1995-1997

Tab. 14. Evolução da mortalidade de mulheres com idade igual ou superior a 50 anos, na Região Metropolitana , nos triênios (1979-1981; 1984-1986; 1990-1992; 1995-1997). .46

Fig. 14. Evolução da mortalidade de mulheres com idade igual ou superior a 50 anos, na Região Metropolitana , nos triênios (1979-1981; 1984-1986; 1990-1992; 1995-1997). 
Tab. 15. Evolução da mortalidade de mulheres com idade igual e superior a 50 anos, no Interior de São Paulo , nos triênios (1979-1981; 1984-1983; 1990-1992; 19951997)

Fig. 15. Evolução da mortalidade de mulheres com idade igual e superior a 50 anos, no Interior de São Paulo , nos triênios (1979-1981; 1984-1986; 1990-1992; 19951997) 47

Tab. 16. Evolução da mortalidade de mulheres com idade igual e superior a 50 anos, no Estado de São Paulo , nos triênios (1979-1981; 1984-1986; 1990-1992; 1995 1997) 48

Fig. 16. Evolução da mortalidade de mulheres com idade igual ou superior a 50 anos, no Estado de São Paulo , nos triênios (1979-1981; 1984-1986; 1990-1992; 1995 1997) 48

Tab. 17. Grupos etários que apresentaram maiores coeficientes de mortalidade em mulheres com idade igual ou superior a 50 anos, na Região Metropolitana, nos triênios (1979-1981; 1984-1986; 1990-1992; 1995-1997)

Fig. 17. Grupos etários que apresentaram maiores coeficientes de mortalidade em mulheres com idade igual ou superior a 50 anos, na Região Metropolitana, nos triênios (1979-1981; 1984-1986; 1990-1992; 1995-1997)

Tab. 18. Grupos etários que apresentaram maiores coeficientes de mortalidade em mulheres com idade igual ou superior a 50 anos, no Interior do estado de São Paulo, nos triênios (1979-1981; 1984-1986; 1990-1992; 1995-1997). .50

Fig. 18. Grupos etários que apresentaram maiores coeficientes de mortalidade em mulheres com idade igual ou superior a 50 anos, no Interior do estado de São Paulo, nos triênios (1979-1981; 1984-1986; 1990-1992; 1995-1997) .50 
Tab. 19. Grupos etários que apresentaram maiores coeficientes de mortalidade em mulheres com idade igual ou superior a 50 anos, no Estado de São Paulo, nos triênios (1979-1981; 1984-1986; 1990-1992; 1995-1997) .51

Fig. 19. Grupos etários que apresentaram maiores coeficientes de mortalidade em mulheres com idade igual ou superior a 50 anos, no Estado de São Paulo, nos triênios (1979-1981; 1984-1986; 1990-1992; 1995-1997) .51

Tab. 20. Grupos etários que apresentaram maiores coeficientes de mortalidade em mulheres com idade igual ou superior a 50 anos, na Região Metropolitana, no Interior do Estado de São Paulo e Estado de São Paulo, nos triênios (1979-1981; 1984-1986; 1990-1992; 1995-1997)

Fig. 20 - grupos etários que apresentaram maiores coeficientes de mortalidade em mulheres com idade igual ou superior a 50 anos, na Região Metropolitana, no Interior do Estado de São Paulo e Estado de São Paulo, nos triênios (1979-1981; 1984-1983; 1990-1992; 1995-1997) 


\section{INTRODUÇÃO}

\subsection{Magnitude do Câncer de Mama no Mundo e no Brasil}

Apesar do expressivo avanço no diagnóstico e tratamento, o câncer de mama representa ainda importante e permanente desafio para os responsáveis em saúde pública. Apresenta-se como a principal causa de óbito feminino por câncer, em países desenvolvidos e a segunda causa em países em desenvolvimento (WHO, 1992 e 1993; GRODSTEIN e col., 1998; FALZONI 2000 ).

Destarte o dramático impacto das terapêuticas adjuvantes - quimioterapia e radioterapia -, as taxas de mortalidade por câncer da mama têm reduzido muito pouco (FALZONI, 2000). Ao se analisarem as taxas apresentadas por diversos países, constatam-se resultados ainda pouco alentadores: na Hungria e Polônia, entre 1964 e 1975, ocorreu aumento de 50\%, enquanto na Europa Ocidental e América do Norte as taxas têm-se mantido estáveis. Na Argentina, Cuba e Uruguai, as taxas de mortalidade por câncer de mama excedem as de câncer cervical (WHO, 1992).

Entre os cânceres, o de mama é o mais prevalente em todo o mundo, atingindo 700.000 casos anuais; a mesma incidência se observa na África, Ásia e Europa Oriental e a maior incidência, na América do Norte, Europa Ocidental (AMERICAN CANCER SOCIETY, 1996). Os resultados demonstram também que a incidência é 50\% maior nas áreas urbanas do que nas rurais, independente de a região ser de alto ou baixo risco (INCA, 1997).

Nos EUA, a incidência do câncer de mama aumentou nas últimas três décadas conforme dados do American Cancer Society (1996) que revelam 1 caso 
para cada 13 mulheres, na década de setenta, 1/11 na década de oitenta e 1/9 na década de noventa (FINOTH e FREITAS JR, 1998). Atualmente, a incidência é de 113 para 100.000 mulheres, constituindo a neoplasia maligna mais freqüente em mulheres acima dos 50 anos e a segunda causa de óbitos por câncer (BORING e Col., 1994; CHUNG e col., 1996; AMERICAN CANCER SOCIETY, 1996).

No Japão, a incidência total de câncer de mama corresponde a 1/5 da verificada nos EUA. Neste, a taxa permanece inalterada entre imigrantes asiáticas e, em particular, japonesas; porém, entre suas descendentes, a incidência aumentou, igualando-se aos índices americanos (HORTOBAGGI, 1995).

No Reino Unido, ocorrem aproximadamente 26.000 novos casos por ano (HORTOBAGGI, 1995). Segundo projeções do CANCER J CLIN, 1995, $1 / 15$ das mulheres na Europa Ocidental irá desenvolver câncer de mama durante sua vida.

O conhecimento epidemiológico sobre a doença mostra que a taxa de mortalidade aumenta progressivamente com a idade (WHO,1992; AMERICAN CANCER SOCIETY, 1996; CHUNG e col., 1996).

No Brasil, dados do Ministério da Saúde, 1998, indicam que o país como um todo apresentou, em termos proporcionais, a maior incidência de câncer de mama do mundo, com variada distribuição entre as capitais. Assim, Porto Alegre (RS) ocupa o primeiro lugar, seguida de Fortaleza (CE), Belém (PA), Goiânia (GO) e da cidade de Campinas, em São Paulo (MINISTÉRIO DA SAÚDE, 1998).

No Estado de São Paulo, nos últimos dez anos, os canceres, sobretudo entre as mulheres, têm representado a segunda causa de morte (SEADE, 1998). Consoante a Décima Classificação Internacional de Doenças (CID-10), no período de 1996 a 
1998, a neoplasia de mama ocupou o $1^{\circ}$ lugar entre os cânceres, tanto na região metropolitana, quanto no interior do Estado.

\subsection{O Câncer de Mama no Contexto da Saúde Pública}

O câncer, de modo geral, está enquadrado entre as doenças crônicas que, de forma evidente, têm aumentado nas últimas décadas, tanto em países desenvolvidos, como naqueles em desenvolvimento, de forma a mudar do perfil de mortalidade (WHO, 1992; BORING e col., 1994; CALDEIRA e BUDIN, 1995; INCA, 1997; LANDIS e col., 1998; REYNOLDS, 1999; BRETT, 1999).

A industrialização, a urbanização e o aumento da expectativa de vida parecem ter estreita relação com o incremento da incidência e mortalidade por câncer de mama. É também mais prevalente em mulheres de melhores condições sociais (HALBE, 1992; WHO, 1992; GARBER, 1996; LANDIS e col., 1998; BOWER e col., 2000).

Também em países em desenvolvimento, o câncer de mama é a neoplasia mais freqüentemente encontrada em mulheres - com prevalência de $40 \%$, responsabilizando-se por 1 a $3 \%$ de todas as mortes (WHO, 1992; AMERICAN CANCER SOCIETY, 1996; CHUNG e col., 1996).

Nos EUA, embora a incidência de câncer de mama tenha aumentado, o maior incremento refere-se ao carcinoma in situ. No período de 1991 a 1995, a taxa de mortalidade diminuiu 4,6\%, em função, muito provavelmente, do maior número de informações sobre a afecção, do melhor rastreamento e dos avanços no tratamento da doença. Em outros países, entretanto, a taxa de mortalidade ainda se mantém 
inalterada, provavelmente devido à inexistência de uma prevenção primária adequada (WHO, 1992; AMERICAN CANCER SOCIETY, 1996; CHUNG e col., 1996; GOTZSCHE \& OLSEN, 2000).

Em relação às taxas de mortalidade por câncer de mama, pode-se dizer que o Brasil se equipara aos EUA (SHAPIRO e col., 1998). O câncer de mama representa a primeira causa de mortalidade em mulheres com idade igual e superior a 50 anos, tanto no Brasil quanto no Estado de São Paulo. No caso de mortalidade específica por câncer, é sabido que, tanto nacional, quanto internacionalmente, trata-se de causa de óbito, cuja declaração é preenchida com maior precisão (LAURENTI, 1973; DOLL e PETO, 1981), contribuindo, assim, para que as estatísticas de mortalidade por câncer estejam entre as mais fidedignas.

Lamentavelmente, em 80 a $85 \%$ do total de casos, o diagnóstico do câncer de mama, vem sendo feito tardiamente (estádios clínicos III e IV), quando as esperanças de cura são remotas (GOES JR, 1994; PINOTTI e TEIXEIRA, 2000).

A probabilidade de câncer mamário aumenta com a idade, sobretudo após a menopausa, embora existam variações entre os diversos países. Notadamente após os 50 anos de idade, observa-se considerável aumento no número de casos, com pico aos 75 anos, seguido de declínio (HENDERSON, 1993).

Estudos revelam que a incidência de câncer de mama pós-menopausa é menor entre mulheres negras e hispânicas do que em mulheres brancas, porém o índice de sobrevida é menor naquelas mulheres, dado que a afecção vem sendo diagnosticada em um estádio mais avançado. O índice de sobrevida de 5 anos para mulheres negras é de 64\%, e para mulheres brancas, de 80\% (ELLEDGE, 1993). 
Em relação à mortalidade por câncer de mama, a literatura revela controvérsias quanto à tendência. Assim, AUDENT-LEPOINTRE (1996) apontam declínio lento nos últimos 50 anos, enquanto KATZ (1997) demonstra não só um incremento da incidência do câncer de mama em vários países, a uma taxa de $1 \%$ a $2 \%$ ao ano, mas também aumento concomitante na taxa de mortalidade, resultado que contrasta com a diminuição das taxas de mortalidade por outros tipos de câncer, o que pode expressar a dificuldade existente em prevenir e em diagnosticar precocemente a doença.

Nos EUA, essas taxas diminuíram de 2.000-3.000 óbitos por ano. Isto também foi documentado na Suécia (HORTOBAGGI, 1995).

Na América do Norte, a redução nas taxas de mortalidade vem sendo atribuída não somente ao screening mamário, mas também à adoção generalizada da quimioterapia adjuvante (NATIONAL CANCER INSTITUTE, 1998). Segundo KONING, 2000, esses mesmos motivos explicam a recente redução na mortalidade por câncer de mama, também constatada no Reino Unido e na Holanda. Entretanto, na Suécia, até 1995, apesar do "screening" mamário, não se observou redução nas taxas de mortalidade por câncer de mama

\subsection{Fatores Etiopatogênicos e Fatores de Riscos}

A elevada e preocupante incidência, os enormes custos sociais, as desastrosas conseqüências físicas, psíquicas e os altos índices de mortalidade conferem ao câncer de mama características de grave problema de saúde pública mundial. A complexidade da doença, associada ao mau prognóstico, têm incentivado 
a identificação de fatores que permitam a melhor compreensão do seu comportamento biológico (BARACAT, 1990).

Entre os principais fatores de risco desvelados por estudos epidemiológicos, destacam-se a idade avançada, história de câncer na mama contralateral, paridade, idade no primeiro parto, exposição a altas doses de radiação (100 rads ou mais) no tórax ou na mama, história familiar de câncer da mama em parente de primeiro grau, situação sócio-econômica, obesidade, dieta hipergordurosa e o antecedente de câncer de ovário ou de endométrio (BOICE e MORSAN, 1977; HENDERSON, 1993; SPRATT, 1995; PINOTTI e TEIXEIRA, 2000).

A idade avançada representa importante fator de risco do câncer de mama; assim, a incidência e.leva-se após a menopausa, alcança pico aos 75 anos e declínio nas idades posteriores (HENDERSON, 1993; XAVIER e XAVIER, 1996).

A idade da menarca, da menopausa, o estado civil e a raça branca são outros fatores de risco, porém de menor relevância (STOCKS, 1982; HARDY e col., 1990). A menarca precoce proporciona maior exposição do epitélio mamário aos hormônios esteróides sexuais que, sabidamente, é considerado um dos fatores der risco mais importantes para eclosão do câncer de mama (CARVALHO, 1992; SPEROFF, 1995; XAVIER e XAVIER, 1996).

Fatores de risco podem atuar de forma isolada ou sincrônica na gênese do câncer de mama, principalmente no período denominado "janela" biológica, que corresponde ao intervalo entre o início da puberdade e a idade de 20 anos (XAVIER e XAVIER, 1996). As evidências epidemiológicas apontam que o grande intervalo entre a menarca e a primeira gestação podem favorecer a ação de fatores que aumentam o risco de o câncer de mama. Consoante XAVIER e XAVIER (1996), 
uma mulher cuja primeira gestação ocorre aos 35, apresenta $40 \%$ maior risco, quando comparada com aquela que teve seu primeiro filho aos 20 anos

Outro importante fator de risco postulado para o câncer de mama é a história familiar. Mulheres, cujas mães ou irmãs tiveram câncer de mama, têm maior probabilidade de desenvolver a doença. O risco de câncer mamário para uma mulher que não tenha parente em primeiro grau que tenha contraído a doença é de 1,5 e, para aquelas, cujas mães ou irmãs foram afetadas, o risco é de 2,4 (MILAN e col., 1998).

Outra constatação epidemiológica interessante: irmãs de pacientes com câncer de mama bilateral, diagnosticado entre os 40 e 50 anos de idade, apresentam risco reduzido pela metade, quando comparadas com irmãs de mulheres com doença bilateral diagnosticada aos 40 anos ou menos. Entretanto, irmãs de pacientes com câncer de mama unilateral, diagnosticado aos 50 anos ou mais, não parecem ter risco significativamente aumentado ( MILAN e col., 1998).

Apesar do exposto, estudos recentes mostram que o risco genético do câncer de mama apresenta freqüência muito baixa, provavelmente menor do que 3\% (HENDERSON, 1993). De fato, estudos de GAIL e BENICHOU (1994) constataram que mulheres com apenas uma parente de primeiro grau com câncer de mama apresentam risco semelhante ao da população geral.

Apesar de certos tipos de doenças benignas da mama poderem significar maior risco para o câncer de mama, no entanto, até o momento não existem evidências que confirmem tal fato.

É fato conhecido que câncer de mama é uma doença que sofre influências hormonais. Por isso, são relatados como fatores de risco, a idade da primeira gravidez, idade da menarca e da menopausa, situações de importantes flutuações 
hormonais. Esses fatores não são suscetíveis a direcionarem modificações e, assim, oferecem pouca possibilidade de redução de incidência ou mortalidade por estratégia de saúde pública.

Um dos fatores de risco de maior controvérsia e preocupação entre mulheres e profissionais de saúde é o uso de esteróides sexuais, sob a forma de contraceptivos orais ou de reposição hormonal no climatério (STEINBERG e col., 1991; HARDY e col., 1990; ALDRIGHI, 1992 e 1996; CARVALHO, 1992; COLDITZ e col., 1995; HARDING, 1996; BARROS e PINOTTI, 1994; FREITAS, 1998; HALBE, 1999).

Essa questão merece cuidado, quando se tem a informação de que mais de 80 milhões de mulheres no mundo usam contraceptivos orais e que cerca de $51 \%$ das mulheres na pós-menopausa fizeram uso de estrógenos durante, pelo menos, três meses (HARDY e col., 1990).

Várias meta-análises têm analisado o risco de câncer de mama em usuárias de reposição hormonal no climatério (STEINBERG e col., 1991; COLDITZ e col., 1993; HULKA e col., 1994; COLDITZ e col., 1995; KENEMANS e col., 1997, SPRITZER e REIS, 1998), concluindo verificar-se aumento do risco em usuárias por longos períodos (acima de dez anos) (DI SAIA e col., 1995; COLDITZ e col., 1995; LOBO,1995; SCHAIRER e col., 1999). Outros autores, entretanto, revelam incremento no risco a partir de cinco anos de uso, em idades entre 55 e 59 anos (GORSKY, 1994; HULKA e col., 1994; COLDITZ e col., 1995).

Existem, ainda, diversas controvérsias sobre as ações dos esteróides sexuais nas mamas. Conseqüentemente, também existem muitas controvérsias sobre o risco de desenvolvimento de câncer mamário em mulheres tratadas com hormônios sexuais (ALDRIGHI, 1996; DE LUCA e col., 1998; SPRITZER e REIS, 1998; 
STOMPER e col., 1990; BARACAT e col., 1998; STANFORD, 1995; MONSEES e col., 1998).

Nos Estados Unidos, o desenvolvimento de programas de screening mamográfico tem sido responsabilizado pelo declínio da mortalidade por câncer, graças à detecção e tratamento precoce (GREENBAUM, 2000). Diretrizes recentemente atualizadas da American Cancer Society (1999) recomendam que as mulheres devem fazer mamografias anuais a partir dos 40 anos de idade e o National Cancer Institute (1998) preconiza mamografias a cada um ou dois anos para mulheres no início de sua quarta década de vida e, anualmente, após os 50.

\section{Fito-estrogênios}

São substâncias naturais derivadas das plantas e apresentam estrutura semelhante ao estrogênio e que fazem parte da nossa dieta (QUELLA, 1999).

Os trabalhos de INGRAM, 1977, em que através de estudo caso-controle, avaliou a associação entre a ingestão de fito-estrogênios (medida através de excreção urinária) e o risco de câncer de mama. Foram incluídos 144 pares para análise. Os controles foram pareados por idade. As mulheres com câncer de mama, recém diagnosticadas, antes de receber qualquer tratamento, forneceram coleta de urina de 72 horas e amostra de sangue. Após ajuste para idade e menarca, paridade, ingestão de álcool, e ingestão total de gordura, a alta excreção de fito-estrogênios, particularmente o fito-estrogênio isoflavônico equol e a lignana enterolactona, foi associada a uma redução substancial no risco de câncer de mama.

Dietas ricas em produtos de soja e óleos de peixe parecem ser preventivos (SILVA e ZURRIDA, 2000). 


\subsection{Rastreamento, Detecção e Diagnóstico Precoce}

Do ponto de vista prático, até o momento, não há como prevenir a moléstia, porém há maneiras de detectá-la em época oportuna, melhorando a sobrevida e a qualidade de vida das mulheres (SOUEN (a), 1998; PINOTTI e TEIXEIRA, 2000).

Apesar do desenvolvimento de novas técnicas cirúrgicas e dos avanços em quimioterapia e radioterapia, observa-se que a mortalidade por esta afecção mantémse em um patamar pouco variável. No entanto, quando detectados e tratados precocemente, as taxas de mortalidade reduzem de forma significativa (STOCKS, 1992; WHO, 1992; MURPHY e col., 1995 SOUEN, 1996; SHAPIRO e col., 1998; MARTORELLI FILHO, 2000; PINOTTI e TEIXEIRA, 2000; GREENBAUN, 2000)

Atualmente, a detecção precoce do câncer de mama baseia-se em três passos: o auto-exame das mamas, o exame físico realizado por profissional treinado e a mamografia. Destes, o único que tem se mostrado efetivo na redução da mortalidade é a mamografia (MORKOVITS, 1988; WHO, 1992; GOES, 1994; SOUEN (b), 1998; MARTORELLI FILHO, 2000; GOTZSCHE e OLSEN, 2000).

O auto-exame das mamas não requer o concurso do médico nem de exames subsidiários e seu custo é nulo. Apesar de críticas, o auto-exame deve ser sempre ensinado, mas não supervalorizado (AUSTOKER, 1994, NEWCOMB e col., 1995; PINOTTI e TEIXEIRA, 2000). Consoante MARTORELLI FILHO (2000), o autoexame deve ser difundido, pois em $95 \%$ dos casos, os sinais suspeitos de câncer são identificados pela própria paciente, sendo que em $65,3 \%$ desses casos confirmou-se a presença do tumor. 
Por isso, o auto-exame, não obstante não permitir a detecção precoce, deve ser estimulado, objetivando detectar neoplasia na sua fase mais incipiente (PINOTTI, 1991, WHO, 1992; AUSTOKER, 1994; NEWCOMB e col., 1995).

A mamografia é considerada o melhor método para a detecção precoce do câncer de mama, até o presente momento. As lesões detectadas pela mamografia têm, em média, diâmetro menor a $0,5 \mathrm{~cm}$ e por isso, com menor probabilidade de serem metastáticas (LESTER,1984; SHAPIRO e col., 1988; MURPHY e col., 1995; GOES, 1994; THOMAS e col., 1997; CARVALHO, 1997; SOUEN (b), 1998; NATIONAL CANCER INSTITUTE, 1998; GOTZSCHE e OLSEN, 2000; TABAR e col., 2000).

Estudos com mulheres acima de 50 anos de idade, submetidas à mamografia, revelaram diminuição de mortalidade de 32\% (SEIDMAN e col., 1987; FEIG, 1998; SOUEN, 1996). BAKER (1992), por sua vez, demonstrou que em 20 a $42 \%$ dos casos, o tumor havia sido detectado somente pela mamografia.

Do ponto de vista técnico, há que se lembrar que não há diferença significativa na imagem mamográfica do tecido mamário de mulheres entre 40-49 anos, em comparação com mulheres entre 50-59 anos. As mamas não são substituídas por gorduras no momento da menopausa ou aos 50 anos de idade. Há um aumento no conteúdo de gordura da mama, mas este é gradual (KOPANS, 1994).

Em função do aumento do número de mulheres que fazem mamografias, ocorre expressivo incremento no diagnóstico de lesões não-palpáveis, elevando, com isso, o número de biópsias. Embora a sensibilidade da mamografia na detecção do câncer de mama se aproxime de $90 \%$, o valor prognóstico positivo é muito menor (de $15 \%$ a $30 \%$ ). Isso resulta na indicação de muitas biópsias, o que pode acarretar um excessivo custo para o sistema de saúde pública. 


\section{Biópsia guiada por imagem - câncer de mama}

A core-biopsy guiada por imagem já mostrou ser técnica segura e precisa para se fazer o diagnóstico histológico, na maior parte de pacientes portadoras de lesões detectadas em mamografias. É uma alternativa à biópsia por excisão cirúrgica, para avaliação de lesões não-palpáveis detectadas por mamografia. Embora a biópsia de massas palpáveis também possa ser efetuada por via percutânea, a orientação por imagem não se faz necessária em muitos casos, e muitos cirurgiões preferem a excisão completa da lesão palpável. As biópsias por core-biopsy já mostraram serem seguras e precisas (de 94\% a 97\%), equiparadas à excisão cirúrgica na coleta de amostras de lesões da mama, com a vantagem de seus custos que correspondem a uma economia de 50\% em relação à biópsia por excisão cirúrgica. Além disso, a biópsia percutânea resulta em menor morbidade. As complicações, pouco freqüentes, correspondem a hematoma e infecção. Como o procedimento é menos invasivo, observa-se menor incidência de cicatrizes e deformidade da mama, e distorções, passíveis de serem confundidas com novas lesões, em futuras mamografias. Freqüentemente, o procedimento pode ser efetuado no mesmo dia em que a lesão é detectada, resultando em diagnóstico mais precoce. Pode ser realizado com a paciente em posição ventral ou sentada, sob orientação mamográfica, fornecida através de técnica estereotáxica ou com a paciente em posição supina sob orientação ultra-sonográfica (SCOTT, 1999; MARTORELLI FILHO, 2000).

Em programas de detecção em massa, visando ao diagnóstico precoce e, conseqüentemente, à redução das taxas de mortalidade, a mamografia constitui, até o momento, a única técnica com eficácia comprovada, simples e confiável (PINOTTI, 
1991; MINISTÉRIO DA SAÚDE, 1998; MENDONÇA, 1995; MURPHY e col., 1995; COOPER, 1994; SOUEN (b), 1998).

As ultra-sonografias, não obstante sua evolução técnica, não permitem visualização eficiente de microcalcificações, um dos achados de maior importância no diagnóstico precoce da neoplasia. A ressonância magnética, por sua vez, é muito recente; por isso, seu valor na propedêutica mamária é discutível (AUDENTLEPOINTRE, 1996; SOUEN (a), 1998).

Apesar de todos os avanços tecnológicos, visando ao diagnóstico, a incidência do câncer de mama vem aumentando, tornando o óbito feminino fenômeno precoce.

Com a preocupação de melhor entender a mortalidade por câncer de mama no Brasil, em particular, de mulheres com idade igual e superior a 50 anos, propusemo-nos realizar o presente estudo no Estado de São Paulo - região metropolitana e interior -, abarcando o período 1979 - 1997, verificando a evolução trienal ocorrida nesse período. Contribuiu para essa delimitação temporal do estudo contar-se com a informação do Ministério da Saúde de uma cobertura de praticamente $100 \%$ dos dados de mortalidade para as- regiões sul e sudeste do Brasil, condição que viabilizaria a realização de nossa proposta.

Dentre as inúmeras indagações de partida e que motivaram nosso estudo, algumas delas podem ser assim resumidas:

1. O comportamento da mortalidade por câncer de mama de mulheres com idade igual e superior a 50 anos, no Estado de São Paulo, no período de estudo, acompanha a tendência crescente descrita na literatura, no plano 
nacional e internacional? Se sim, esse aumento se dá uniformemente para todas as idades que abarca?

2. No Estado de São Paulo, o comportamento da mortalidade em estudo é igual ou distinto, segundo tratar-se de região metropolitana ou interior ?

3. Do ponto de vista das práticas de saúde, que contribuições poderiam ser fornecidas a partir dos resultados encontrados?

Com esse tipo de preocupação, este estudo foi realizado, sobre cujo desenvolvimento apresentamos nos capítulos seguintes. 


\section{OBJETIVO}

Descrever a mortalidade, por câncer de mama, em mulheres com idade igual e superior a 50 anos, no Estado de São Paulo, segundo a região geográfica de residência: Região Metropolitana da Grande São Paulo e Interior do Estado, e sua evolução por triênio, no período de 1979-1997 . 


\section{MÉTODOS}

\subsection{Delineamento do Estudo}

Trata-se de um estudo descritivo de série temporal sobre mortalidade de mulheres com idade igual ou superior a 50 anos.

\subsection{Caracterização das Áreas Estudadas no Estado de São Paulo}

O Estado de São Paulo, localizado na Região Sudeste do Brasil, apresenta área total territorial de $248.808,8 \mathrm{~km}^{2}$, correspondente a $2,91 \%$ da área total do país. É composto por 645 municípios e 225 comarcas, sendo que a Região Metropolitana de São Paulo é constituída de 39 municípios e 20 comarcas e o Interior é composto de 606 municípios e 205 comarcas.

De acordo com dados do IBGE, em 1979, a população em São Paulo era de 23.982.229 habitantes, sendo 11.996 .478 do sexo masculino e 11.806 .440 do sexo feminino. Em 1998, a população era de 35.124.979 habitantes (IBGE - contagem 1996), sendo 17.316.339 do sexo masculino e 17.806.440 do sexo feminino. Em 1996, a esperança de vida ao nascer, no sexo feminino, era de 74,01 anos, diferentemente da do Brasil, que alcançava 71,4. Em 1998, a população em idade ativa estava composta por $51,7 \%$ de ocupados, $10,6 \%$ de desempregados e $37,6 \%$ de inativos. A participação de mulheres no município de São Paulo, com mais de 50 anos era de 40,9\% (SEADE, 1998). Em 1979, a taxa de mortalidade (x 100.000) por câncer de mama em mulheres com mais de 50 anos era de 48,58 anos e em 1998, de 61,70 anos. 
MAPA 


\subsection{População de Estudo}

O estudo proposto abrange mulheres com idade igual ou superior a 50 anos, residentes na Região Metropolitana e no Interior do Estado de São Paulo, e que morreram com câncer de mama, no período de 1979 a 1997.

QUADRO 1 - POPULAÇÃO DE MULHERES COM 50 ANOS OU MAIS E CARACTERÍSTICAS SÓCIO-ECONÔMICAS DAS REGIÕES EM ESTUdO NO ANO DE 1997. ESTADO DE SÃO PAULO, REGIÃo METROPOLITANA E INTERIOR DO ESTADO DE SÃO PAULO

\begin{tabular}{|c|c|c|}
\hline REGIÃO & POPULAC̣̃̃O IBGE 1996 & CARACTERÍSTICAS \\
\hline Estado de São Paulo & 4.454 .438 & $\begin{array}{l}\text { Apresenta a maior renda } \\
\text { "per-capta" do país. A } \\
\text { economia é sustentada pela } \\
\text { agropecuária, indústria e } \\
\text { serviços }\end{array}$ \\
\hline Região Metropolitana & 1.557 .054 & $\begin{array}{l}\text { Apresenta uma das maiores } \\
\text { rendas "per-capta" do país. } \\
\text { Predomínio de indústrias e } \\
\text { serviços }\end{array}$ \\
\hline Interior do Estado de São Paulo & 2.897 .384 & $\begin{array}{l}\text { Os rendimentos provenien- } \\
\text { tes do trabalho, constituem } \\
\text { a parcela mais importante } \\
\text { da renda familiar (69\%); } \\
\text { aposentadorias e pensões } \\
\text { vem em segundo lugar } \\
\text { correspondendo a cerca de } \\
20 \% \text {. Concentra a maioria } \\
\text { das indústrias de } \\
\text { especialização }\end{array}$ \\
\hline
\end{tabular}

FONTE: IBGE 1991 


\subsection{Período de Estudo}

O período de estudo abrange 18 anos consecutivos, compreendidos entre 1979 e 1997. A variável tempo foi agrupada em triênios, conforme abaixo. Este artifício foi utilizado com a intenção de reduzir a possível flutuação dos dados, ano a ano.

Para melhor operacionalização do estudo, optou-se por efetuar a média de cada triênio, conforme esquema abaixo, sendo que, de 1979 a 1992, o estudo foi realizado pela CID-9 e de 1995 a 1997, pela CID-10.

1. 1979 à 1981 - Média do Triênio - CID 9

2. 1984 à 1986 - Média do Triênio - CID 9

3. 1990 à 1992 - Média do Triênio - CID 9

4. 1995 à 1997 - Média do Triênio - CID 10

\subsection{Variáveis de Estudo}

Os óbitos de mulheres por câncer de mama com idade igual ou superior a 50 anos foram analisados segundo as variáveis: ano de ocorrência, local de residência e idade. 


\subsection{1 Óbitos de Mulheres por Câncer de Mama}

Foram consideradas todas as declarações de óbito que apresentaram como causa básica de morte o câncer de mama, correspondente ao código 147 da $9^{\mathrm{a}}$ revisão e ao código C50 da 10a revisão da Classificação Internacional de Doenças.

Mediante estudo retrospectivo apresenta-se a partir de 1979 a evolução das taxas de mortalidade por câncer de mama na Região Metropolitana e no Interior do Estado de São Paulo.

\subsubsection{Faixa Etária}

Os grupos etários foram definidos de acordo com os critérios do censo, que agrupa a população de cinco em cinco anos. Assim as mulheres foram divididas em sete subgrupos, a saber: 50-54 anos, 55-59 anos, 60-64 anos, 65-69 anos, 70-74 anos, 75-79 anos, 80 e mais anos de idade.

\subsection{Coleta de Dados}

A coleta foi realizada a partir do Banco de Dados do Sistema de Informação Sobre Mortalidade (SIM) - DATASUS/CENEPI, composto por dados de declaração de óbito dos anos de 1979 a 1997. Esse banco de dados contém informações fornecidas pelas Secretarias Estaduais de Saúde ao Ministério da Saúde, através de seus órgãos: Secretaria Executiva/DATASUS e Fundação Nacional de Saúde/CENEPI. A organização das informações de todo o país no Sistema de 
Informação de Mortalidade (SIM) apresenta-se como instrumento que favorece o planejamento e o controle social das ações em saúde, pois possibilita a caracterização do perfil epidemiológico e o retorno ágil das informações à comunidade. Outra fonte de dados foram os Censos Demográficos dos anos 1970, 1980, 1991 (IBGE, 1973, 1983 e 1993) e da Contagem Populacional realizada em 1996 (IBGE, 1997). Esta fonte é importante para o cálculo de projeções para $1^{\circ}$ de julho dos anos de estudo, mediante o uso de interpolação pelo método de Lagrange (CLAUDIO e MARINS, 1989). Outras fontes subsidiárias foram buscadas, à medida do desenvolvimento do projeto, sempre que se apresentou a necessidade de complementar o estudo proposto.

\subsubsection{Especificação das tabelas que deram suporte à análise dos dados}

1) Tabelas do total e percentual de óbitos por câncer de mama, SEXO (feminino); LOCAL DE RESIDÊNCIA (Estado de São Paulo: Região Metropolitana e Interior); e FAIXA ETÁRIA ( 50 anos e mais), nos anos 1979 a 1996 - (CID 9-3 dígitos do Capítulo II Neoplasmas).

2) Tabelas do total e percentual de óbitos por câncer de mama, SEXO (feminino); LOCAL DE RESIDÊNCIA (Estado de São Paulo: Região Metropolitana e Interior); e FAIXA ETÁRIA ( 50 anos e mais), nos anos de 1997 (CID 10-3 dígitos do Capítulo II Neoplasmas). 


\subsection{Apresentação e Análise dos Dados Estatísticos}

Inicialmente, procedeu-se a apresentação dos dados de mortalidade, por câncer de mama, de mulheres com idade igual ou superior a 50 anos, no Estado de São Paulo, do período de estudo, com distribuição de frequiências e cálculo dos coeficientes brutos de mortalidade. Foram calculadas proporções e taxas ou coeficientes para cada ano calendário e valores médios para os seis triênios .

As médias dos coeficientes de mortalidade, por câncer de mama, de mulheres de 50 anos ou mais, foram calculadas utilizando-se, no numerador, a soma dos óbitos femininos por câncer de mama ocorridos em cada triênio, e no denominador, o número estimado da população feminina no mesmo triênio a seguir, foram feitos os cálculos dos coeficientes de mortalidade por câncer de mama específicos para cada faixa etária definida, conforme a técnica de padronização pelo método direto (LAURENTI e col., 1987).

Para controlar as possíveis diferenças nas estruturas etárias das populações das duas áreas de estudo, os coeficientes de mortalidade foram padronizados, tomando-se como padrão a população total do Estado de São Paulo, obtida pelo censo de 1991 (IBGE, 1998). Para possíveis comparações, com resultados de outros trabalhos, esses coeficientes também foram padronizados, tomando-se como padrão a população mundial (ROUQUAYROL \& KERR-PONTES, 1994), permitindo dessa forma a comparação internacional dos resultados obtidos.

Para o Estado de São Paulo, os coeficientes foram padronizados pela população do Estado no censo de 1991 e pela população mundial. 


\section{RESULTADOS}

\subsection{Resultados Obtidos para o Estado de São Paulo - Região Metropolitana e Interior}

\section{Mortalidade por câncer de mama de mulheres com idade igual e superior a 50 anos, para o Estado de São Paulo}

Em todo o Estado de São Paulo nos quatros triênios estudados (1979-1981, 1984-1986, 1990-1992 e 1995-1997), foram constatados 14.830 óbitos por câncer de mama, com a seguinte distribuição: 2.399 (16,18\%) no primeiro triênio, 3.146 $(21,21 \%)$ no segundo triênio, $4.096(27,62 \%)$ no terceiro triênio e $5.189(34,99 \%)$ no quarto triênio.

Observa-se que houve expressivo aumento do número desses óbitos, do primeiro para o quarto triênio, da ordem de $116,3 \%$.

A distribuição dos óbitos por câncer de mama, por faixa etária, nos quatro triênios foi: $2.593(17,48 \%)$ entre 50-54 anos; $3.129(21,10 \%)$ entre 55-59 anos; $2.026(13,66 \%)$ entre 60-64 anos; $2.643(17,82 \%)$ entre $65-69 ; 1.534(10,34 \%)$ entre $70-74 ; 1.521(10,26 \%)$ entre $75-79$ anos; $1.384(9,34 \%)$ entre 80 e mais.

A TABELA 1 e FIGURA1, referentes ao número e porcentagem de óbitos por câncer de mama, segundo grupos etários e triênios estudados, mostram que a proporção de óbitos por câncer de mama na faixa etária 75 e mais anos aumentou significativamente de triênio para triênio: primeiro triênio - 266 óbitos ( 11,09\%); segundo - 577 óbitos ( $18,34 \%)$; terceiro- 856 óbitos ( 20,90\%) e 1206 (23,24\%) 
no quarto triênio. Já no grupo etário de 50-54 anos observou-se decréscimo na proporção de óbitos de $21,89 \%$ no primeiro triênio, para $16,03 \%$ no último triênio, ou seja, decréscimo de 5,86\%, seguida da faixa etária de 55-59 anos, que apresentou decréscimo de 4,14\%. Na faixa etária 60-64 anos, observa-se aumento no percentual de óbitos de 2,46\%, entre o primeiro e quarto triênio, diminuindo nas faixas etárias 65-69 anos e 70-74 anos, e elevando-se após 75 anos. 
TABela 1 - Número E PORCENTAgem de Óbitos POR CÂNCER de MAMA DE MULHERES COM IDADE IGUAL E SUPERIOR A 50 ANOS, SEGUNDO GRUPOS ETÁRIOS, NOS TRIÊNIOS 1979-1981, 1985-1986, 1990-1992 E 1995-1997, NO ESTAdo de SÃo PAUlo

\begin{tabular}{|c|c|c|c|c|c|c|c|c|}
\hline \multirow[t]{2}{*}{$\begin{array}{l}\text { Grupo } \\
\text { Etário }\end{array}$} & \multicolumn{2}{|c|}{$\begin{array}{c}\text { Primeiro Triênio } \\
(1979-1981)\end{array}$} & \multicolumn{2}{|c|}{$\begin{array}{l}\text { Segundo Triênio } \\
(\mathbf{1 9 8 4 - 1 9 8 5 )}\end{array}$} & \multicolumn{2}{|c|}{$\begin{array}{c}\text { Terceiro Triênio } \\
(1990-1992)\end{array}$} & \multicolumn{2}{|c|}{$\begin{array}{c}\text { Quarto Triênio } \\
\text { (1995-1997) }\end{array}$} \\
\hline & $\mathbf{N}$ & $\%$ & $\mathbf{N}$ & $\%$ & $\mathbf{N}$ & $\%$ & $\mathbf{N}$ & $\%$ \\
\hline $50-54$ anos & 525 & 21,89 & 527 & 16,75 & 709 & 17,31 & 832 & 16,03 \\
\hline $55-59$ anos & 559 & 23,30 & 708 & 22,51 & 868 & 21,19 & 994 & 19,16 \\
\hline 60-64 anos & 274 & 11,42 & 463 & 14,71 & 569 & 13,89 & 720 & 13,88 \\
\hline 65-69 anos & 444 & 18,5 & 563 & 17,90 & 696 & 16,99 & 940 & 18,11 \\
\hline 70-74 anos & 331 & 13,8 & 308 & 9,79 & 398 & 9,72 & 497 & 9,58 \\
\hline 75-79 anos & 148 & 6,17 & 320 & 10,17 & 462 & 11,28 & 591 & 11,39 \\
\hline 80 e mais & 118 & 4,92 & 257 & 8,17 & 394 & 9,62 & 615 & 11,85 \\
\hline Total & 2399 & 100 & 3146 & 100 & 4096 & 100 & 5189 & 100 \\
\hline
\end{tabular}

FIGURA 1 - NÚMERo DE ÓbITOS DE CÂNCER DE MAMA DE MULHERES COM IDADE IGUAL E SUPERIOR A 50 ANOS, SEGUNDO GRUPOS ETÁRIOS, NOS TRIÊNIOS 19791981, 1985-1986, 1990-1992 E 1995-1997, NO ESTADO DE SÃo PAULO.

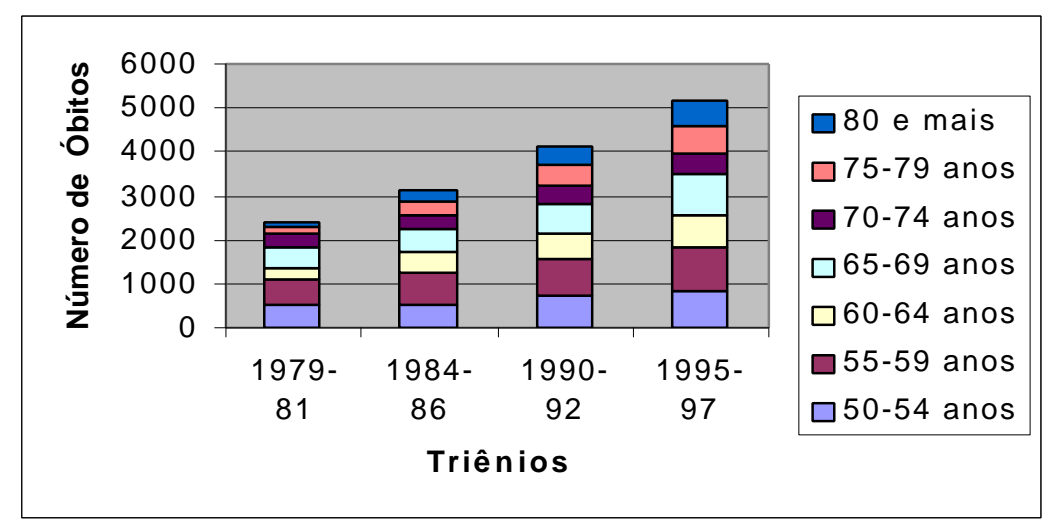


Ao levar em conta a população feminina paulista, com idade igual e superior a 50 anos, no período estudado, constata-se que houve aumento de $44,82 \%$, segundo os censos de 1980 e 1991. Com a estratificação dessa população em grupos etários, verifica-se a seguinte distribuição: 50 a 54 anos - 24,17\%; 55 a 59 anos - 40,18\%; 60 a 64 anos - 57,51\%; 65 a 69 anos - 50,01\%; 70 a 74 anos - 60,25\%; 75 a 79 anos $-61,69 \%$ e 80 e mais anos de idade $-85,69 \%$ (TABELA 2 e FIGURA 2). 
TABELA 2 - POPUlAÇÃo FEMININA, A PARTIR DE 50 ANOS DE IDADE, NOS CENSOS DE 1980 E 1991, ESTRATIFICADA POR FAIXA ETÁRIA, NO ESTADO DE SÃO PAULO

\begin{tabular}{c|cc|cc}
\hline Faixa & \multicolumn{2}{|c|}{$\mathbf{1 9 8 0}$} & & \multicolumn{2}{c}{$\mathbf{1 9 9 1}$} & $\mathbf{N}$ \\
\hline $50-54$ anos & $\mathbf{N}$ & $\mathbf{\%}$ & 615163 & 24,82 \\
\cline { 2 - 5 } $55-59$ anos & 374727 & 28,95 & 525284 & 21,20 \\
$60-64$ anos & 292337 & 21,90 & 460453 & 18,58 \\
$65-79$ anos & 227683 & 17,08 & 341554 & 13,78 \\
$70-74$ anos & 144663 & 13,30 & 231826 & 9,35 \\
$75-79$ anos & 98559 & 8,45 & 159356 & 6,43 \\
80 anos e + & 77916 & 5,76 & 144680 & 5,84 \\
\hline Total & 1.711 .296 & 4,55 & 2.478 .316 & 100,00 \\
\hline
\end{tabular}

Fonte: IBGE - Censos de 1980 e 1991

Figura 2 - POPUlAÇão FEMinina, A PARTIR DE 50 ANOS DE IDADE, ESTRATIFICADA POR GRUPOS ETÁRIOS, NOS ANOS DE 1980 E 1991, NO ESTADO DE SÃO PAULO

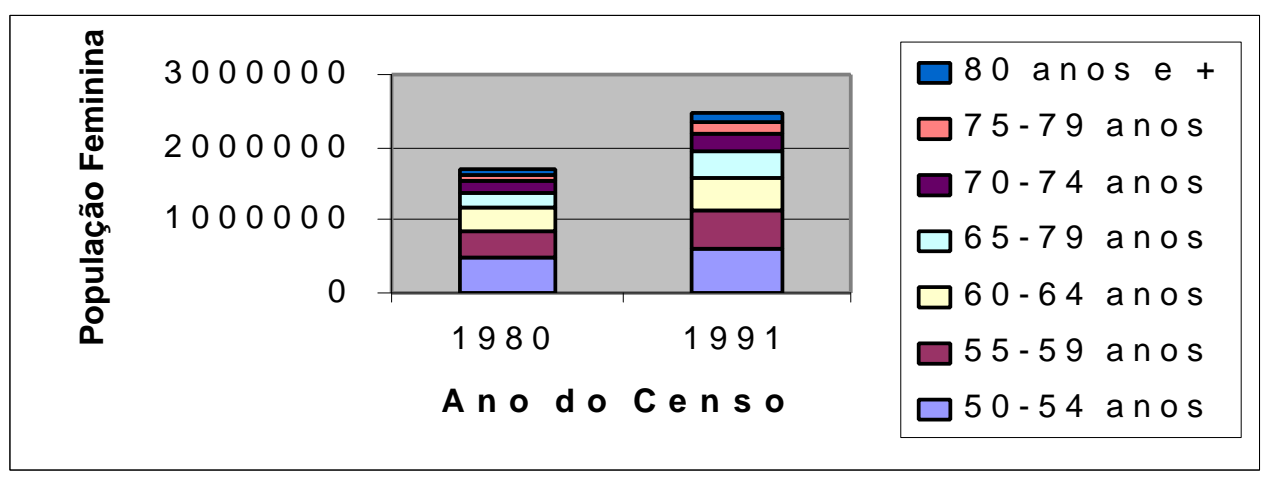


O coeficiente bruto de mortalidade por câncer de mama, calculado para os triênios 1979-1981; 1984-1986; 1990-1992 e 1995-1997, no Estado de São Paulo, foi de 46,62/100.000 mulheres, 49,58/100.000 mulheres, 55,09/100.000 mulheres e 60,61/100.000 mulheres, respectivamente.

O comportamento das taxas de mortalidade indica que o risco de morrer por câncer de mama no Estado variou entre os grupos etários durante o período estudado. Observa-se diminuição do risco de morte por essa neoplasia nos grupos etários de 50-59 anos e aumento entre 60-69 anos. A variação do risco entre o primeiro e o quarto triênio foi de $30,01 \%$

As taxas de mortalidade específica por faixas etárias, calculadas para os quatro triênios, evidenciaram que o risco de morrer por câncer de mama não aumentou continuamente com a idade, oscilando entre os grupos etários. Mostrou-se mais baixo nos grupos etários 50-54 e 55-59 anos, aumentando entre 60-64 anos, voltando a diminuir entre 65-69 e 70-74 anos, e aumentando após 75 anos (TABELA 4). Semelhante comportamento recomenda que possíveis variações na estrutura etária da população sejam levadas em consideração nas comparações (no período estudado, houve aumento da proporção de mulheres a partir de 50 anos de 44,82\% - TABELA 2). Para contornar essas variações, apura-se para os diferentes triênios a taxa de mortalidade padronizada para uma estrutura etária constante. A TABELA 3 apresenta evolução das taxas brutas de mortalidade por câncer de mama, padronizadas de acordo com uma única estrutura etária (observada no Estado de São Paulo em 1991). 
TABEla 3 - COEFICIENTE (BRUTO E PADRONIZAdo POR IDAdE DA POPUlaÇÃo FEMININA COM MAIS DE 50 ANOS DE IDADE NO ESTADO DE SÃO PAUlo EM 1991) DE MORTALIDAde POR CÂNCER DE MAMA NOS TRIÊNIOS 1979-1981, 1984-1986, 1990-1992 e 1995-1997.

\begin{tabular}{|c|c|c|}
\hline Triênio & $\begin{array}{c}\text { Coeficiente bruto de } \\
\text { mortalidade }\end{array}$ & $\begin{array}{l}\text { Coeficiente padronizado } \\
\text { (pela população } \\
\text { feminina de São Paulo - } \\
1991)\end{array}$ \\
\hline $1979-81$ & 46,62 & 48,11 \\
\hline $1984-86$ & 49,58 & 49,84 \\
\hline $1990-92$ & 55,09 & 55,09 \\
\hline $1995-97$ & 60,61 & 60,13 \\
\hline
\end{tabular}

FIGURA 3 - COEFICIENTE (BRUTO E PADRONIZAdo POR IDAdE DA POPUlaÇão FEMININA COM MAIS DE 50 ANOS DE IDADE NO ESTADO DE SÃO PAULO EM 1991) DE MORTALIDADE POR CÂNCER DE MAMA, NOS TRIÊNIOS 1979-1981, 1984-1986, 1990-1992 e 1995-1997.

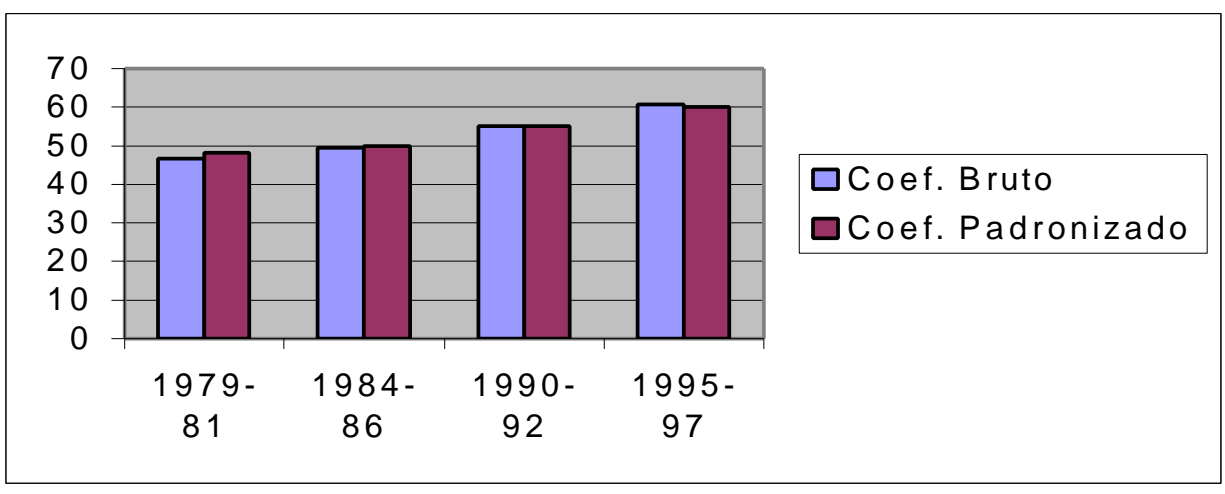

A partir das taxas padronizadas pela população feminina de 1991, evidencia-se a tendência de aumento mais discreto, correspondendo a $24,97 \%$ a 
variação total verificada no período. Diante dessa situação, não se pode afirmar que o aumento da mortalidade por câncer de mama no Estado de São Paulo (taxa bruta) está relacionada somente ao envelhecimento da população. Devem ser considerados, também, o aumento da incidência e a letalidade da doença.

A TABELA 4 e a FIGURA 4 apresentam o comportamento dos coeficientes de mortalidade por câncer de mama, segundo os grupos etários da faixa em estudo. Observa-se maior aumento do valor dos coeficientes de mortalidade por câncer de mama no grupo etário acima de 75 anos. Assim, no último triênio, o grupo etário 7174 anos apresentou o coeficiente de 57,35 por 100.000 mulheres; o grupo 75-80, 108,26 por 100.000 mulheres; 80 anos e mais, 111,22 por 100.000 mulheres. No conjunto da faixa etária de 50 anos e mais verificou-se um crescimento de 47,65\%. 
TABELA 4 - COEFICIENTE DE MORTALIDADE POR CÂNCER DE MAMA (POR 100.000 MULHERES) SEGUNDO GRUPOS ETÁRIOS DA FAIXA DE 50 ANOS E MAIS, NO ESTADO DE SÃo PAULO, NOS TRIÊNIOS 1979-1981, 1984- 1986, 1990 - 1992 e 1995- 1997.

\begin{tabular}{|c|c|c|c|c|c|c|c|c|}
\hline \multirow[t]{2}{*}{$\begin{array}{l}\text { Faixa } \\
\text { Etária }\end{array}$} & \multicolumn{2}{|c|}{ 1979-1981 } & \multicolumn{2}{|c|}{ 1984- 1986} & \multicolumn{2}{|c|}{1990 - 1992} & \multicolumn{2}{|c|}{ 1995- 1997} \\
\hline & $\mathbf{N}$ & Coef. & $\mathbf{N}$ & Coef. & $\mathbf{N}$ & Coef. & $\mathbf{N}$ & Coef. \\
\hline $50-54$ & 175 & 35,33 & 176 & 31,91 & 236 & 38,42 & 277 & 38,85 \\
\hline $55-59$ & 186 & 49,73 & 236 & 52,19 & 289 & 55,09 & 331 & 57,50 \\
\hline $60-64$ & 91 & 31,25 & 154 & 40,29 & 190 & 41,20 & 240 & 48,17 \\
\hline $65-69$ & 148 & 65,01 & 188 & 65,13 & 232 & 67,93 & 313 & 76,44 \\
\hline $70-74$ & 110 & 53,99 & 103 & 55,45 & 133 & 57,23 & 166 & 57,35 \\
\hline $75-79$ & 49 & 73,32 & 107 & 78,75 & 154 & 96,65 & 197 & 108,26 \\
\hline $80 \mathrm{e}+$ & 39 & 73,28 & 86 & 71,09 & 131 & 90,79 & 205 & 111,22 \\
\hline
\end{tabular}

FIGURA 4 - COEFICIENTE DE MORTALIDADE POR CÂNCER DE MAMA (POR 100.000 MULHERES), SEGUNDO FAIXA ETÁRIA, NO ESTADO DE SÃo PAULO, NOS TRIÊNIOS 1979-1981, 1984-1986, 1990-1992 E 1995-1997.

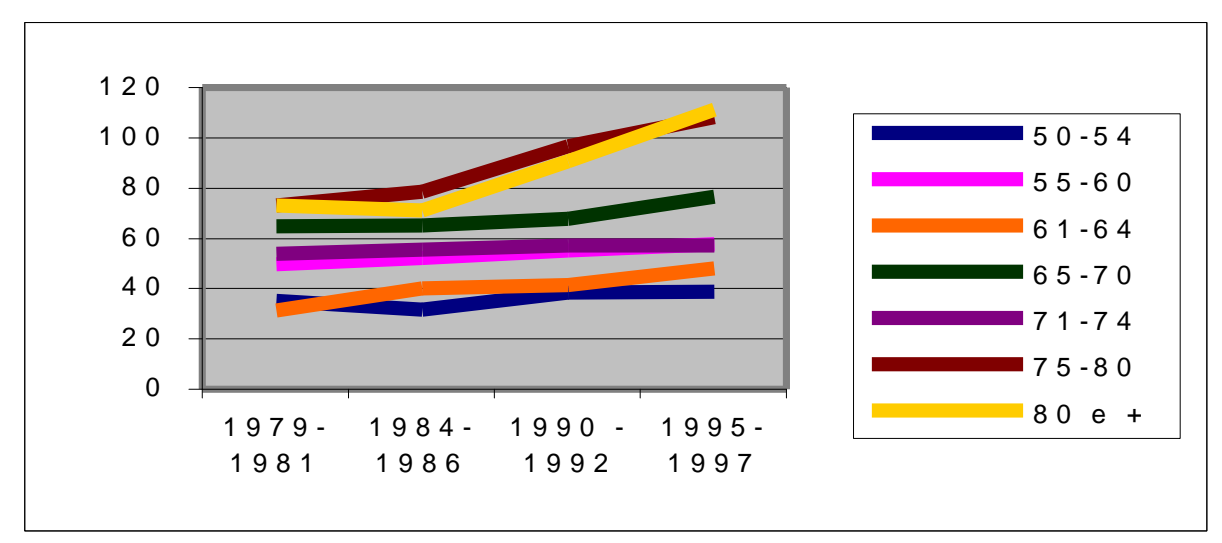


Estudando-se a mortalidade por câncer de mama de mulheres com idade igual e superior a 50 anos, em relação à sua distribuição no Estado de São Paulo, constatase que a região que apresentou o maior número de óbitos por câncer de mama foi a Região Metropolitana, com 8.390 óbitos (56,57\%), enquanto o Interior contou com 6.440 óbitos $(43,43 \%)$. Nos triênios estudados, verifica-se aumento do número de óbitos, em todas as regiões do Estado de São Paulo ( TABELA 5 e FIGURA 5 ). 
TABELA 5 - DISTRIBUIÇÃo (NÚMERO E \% DOS ÓBITOS POR CÂNCER DE MAMA DE MULHERES COM IDADE IGUAL E SUPERIOR A 50 ANOS, SEGUNDO REGIÕES DO ESTADO DE SÃO PAULO, NOS TRIÊNIOS 1979-1981, 19841986, 1990-1992 e 1995-1997.

\begin{tabular}{|c|c|c|c|c|c|c|c|c|c|c|}
\hline \multirow[t]{2}{*}{ Região } & \multicolumn{2}{|c|}{ 1979-1981 } & \multicolumn{2}{|c|}{ 1984-1986 } & \multicolumn{2}{|c|}{ 1990-1992 } & \multicolumn{2}{|c|}{ 1995-1997 } & \multirow{2}{*}{$\begin{array}{l}\text { total } \\
\mathbf{N}\end{array}$} & \multirow{2}{*}{$\begin{array}{l}\% \\
\%\end{array}$} \\
\hline & $\mathbf{N}$ & $\%$ & $\mathbf{N}$ & $\%$ & $\mathbf{N}$ & $\%$ & $\mathbf{N}$ & $\%$ & & \\
\hline $\mathrm{RM}$ & 1402 & 58,44 & 1793 & 57,43 & 2296 & 56,05 & 2899 & 55,61 & 8390 & 56,57 \\
\hline Interior & 997 & 41,56 & 1329 & 42,57 & 1800 & 43,95 & 2314 & 44,39 & 6440 & 43,43 \\
\hline Total & 2399 & 100,0 & 3122 & 100,0 & 4096 & 100,0 & 5213 & 100,0 & 14830 & 100,0 \\
\hline
\end{tabular}

Figura 5 - Distribuição PERCENTUAL do TOTAL de ÓBITOS POR CÂNCER DE MAMA DE MULHERES COM 50 ANOS E MAIS DE IDADE, NAS REGIÕES DO ESTAdo de SÃo PAUlO, NOS TRIÊNIOS 1979-1981, 1984-1986, 19901992 e 1995-1997.

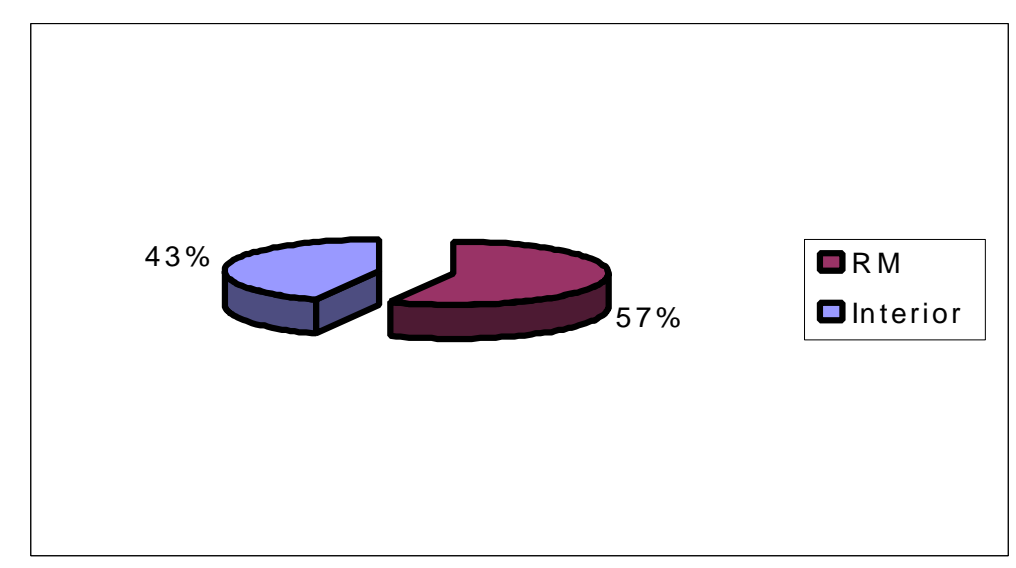

As FIGURAS 5.A, 5.B, 5.C e 5.D se referem aos dados de óbitos por câncer de mama de mulheres com idade igual e superior a 50 anos, no Estado de São 
Paulo, por triênios e distribuição por Região Metropolitana e Interior no período estudado.

FIGURA 5.A - NÚMERO DE ÓBITOS POR CÂNCER DE MAMA DE MULHERES COM IDADE IGUAL E SUPERIOR A 50 ANOS, NA REGIÃo METROPOLITANA E NO INTERIOR DE SÃO PAULO, NO TRIÊNIO 1979-1981

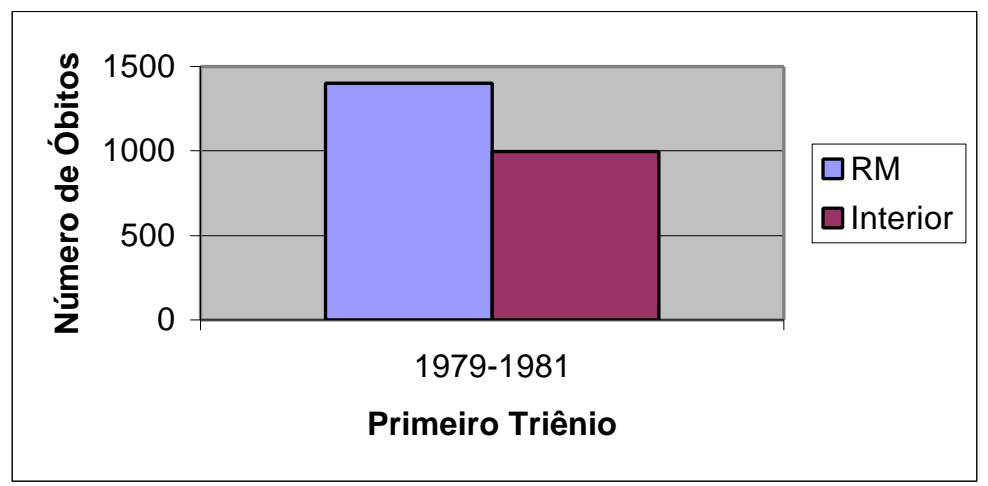

FIGURA 5.B - NÚMERO DE ÓBITOS POR CÂNCER DE MAMA DE MULHERES COM IDADE IGUAL E SUPERIOR A 50 ANOS, NA REGIÃO METROPOLITANA E NO INTERIOR DE SÃO PAULO, NO TRIÊNIO 1984-1986.

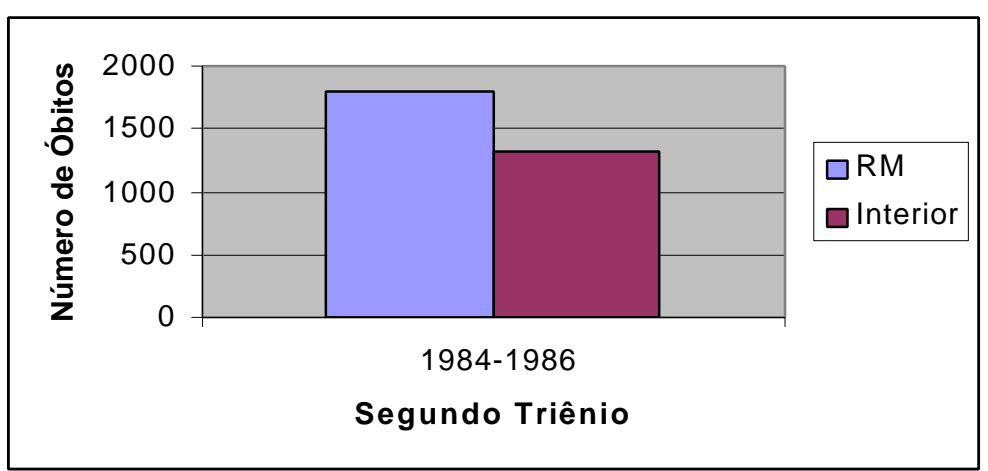


FIGURA 5.C - NÚMERO DE ÓBITOS POR CÂNCER DE MAMA DE MULHERES COM IDADE IGUAL E SUPERIOR A 50 ANOS, NA REGIÃO METROPOLITANA E NO INTERIOR DE SÃO PAULO, NO TRIÊNIO 1990-1992.

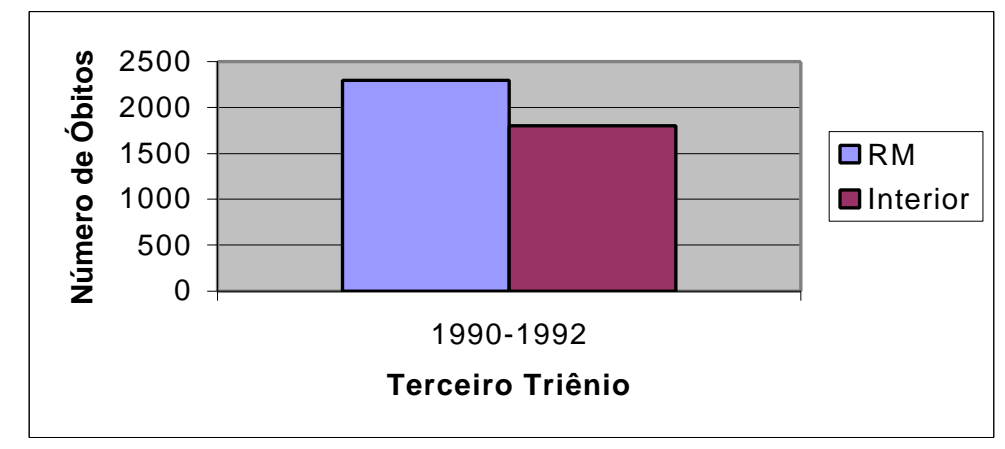

FIGURA 5.D - NÚMERO DE ÓBITOS POR CÂNCER DE MAMA DE MULHERES COM IDADE IGUAL E SUPERIOR A 50 ANOS, NA REGIÃO METROPOLITANA E NO INTERIOR DE SÃO PAULO, NO TRIÊNIO DE 1995 - 1997

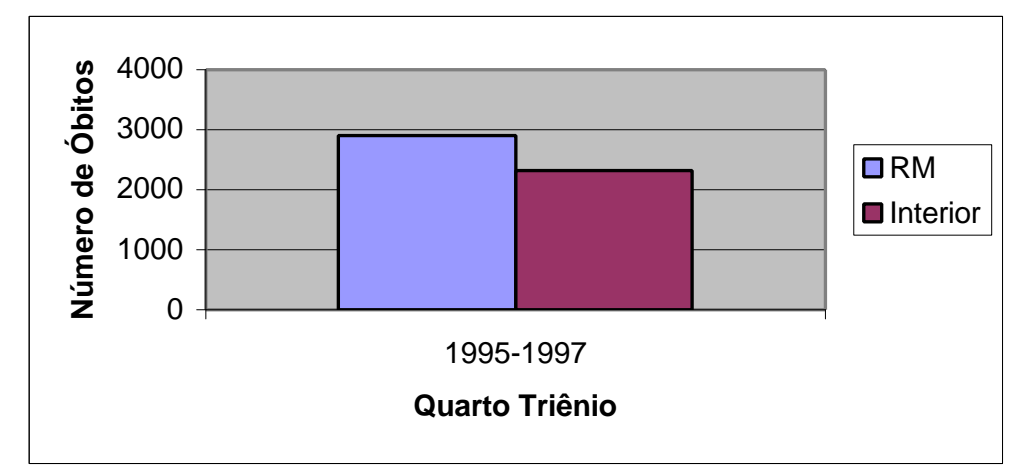

Antes de qualquer comentário a respeito da evolução trienal encontrada para o Estado de São Paulo, no período de estudo, é necessário considerar que a população feminina, da faixa etária de 50 anos e mais, aumentou nas regiões consideradas nesse período. Na Região Metropolitana, o aumento foi de 55,53\% e, no Interior do Estado, 78,41\%, quando comparada a população do $1^{\circ}$ triênio (1979- 
1981) com a do $4^{\text {o }}$ triênio (1995-1997). Com base nesses dados populacionais e no número de óbitos verificado nessa população delimitada, constata-se que a proporção de óbitos por câncer de mama, na faixa etária estudada, diminuiu no decorrer dos triênios na Região Metropolitana, enquanto o Interior do Estado apresentou um aumento nesse período.

Já o coeficiente bruto de mortalidade, por câncer de mama, de mulheres com idade igual e superior a 50 anos, aumentou em ambas regiões estudadas, ao longo dos triênios selecionados (TABELA 6 e FIGURA 6). De fato, no período de 1979-1981 a 1995-1997, a taxa bruta de mortalidade por câncer de mama aumentou $32,95 \%$ na Região Metropolitana, 30,10 \% no Interior e 29,96 \%, no Estado de São Paulo, como um todo. 
TABELA 6 - NÚMERO DE ÓBITOS E COEFICIENTE BRUTO DE MORTALIDADE POR CÂNCER DE MAMA DE MULHERES COM IDADE IGUAL E SUPERIOR A 50 ANOS(POR 100.000 MULHERES) NOS TRIÊNIOS 1979-1981, 1984-1986, 1990-1992 E 1995-1997, E POPULAÇÃo FEMININA DE 50 ANOS E MAIS, DE 1970, 1980, 1991 E CONTAGEM POPULACIONAL DE 1996 ANO DOS CENSOS, SEGUNDO AS REGIÕES DE ESTUdO NO ESTADO DE SÃo PAULO.

\begin{tabular}{|c|c|c|c|c|c|c|c|c|c|c|c|c|}
\hline $\begin{array}{l}\text { Regiã } \\
\text { o }\end{array}$ & $\begin{array}{l}\text { 1979- } \\
1981\end{array}$ & & & $\begin{array}{l}\text { 1984- } \\
1986\end{array}$ & & & $\begin{array}{l}\text { 1990- } \\
1992\end{array}$ & & & $\begin{array}{l}1995- \\
1997\end{array}$ & & \\
\hline & Pop. & $\mathbf{N}$ & Coef & Pop. & $\mathbf{N}$ & Coef & Pop. & $\mathbf{N}$ & Coef & Pop. & $\mathbf{N}$ & Coef \\
\hline RM & $\begin{array}{l}2.510 .17 \\
7\end{array}$ & 1402 & $\begin{array}{l}55,8 \\
5\end{array}$ & $\begin{array}{l}2.984 .04 \\
4\end{array}$ & 1793 & $\begin{array}{l}60,0 \\
9\end{array}$ & $\begin{array}{l}3.512 .98 \\
1\end{array}$ & 2296 & $\begin{array}{l}65,3 \\
6\end{array}$ & $\begin{array}{l}3.904 .21 \\
0\end{array}$ & 2899 & $\begin{array}{l}74,2 \\
5\end{array}$ \\
\hline $\begin{array}{l}\text { Interio } \\
\mathrm{r}\end{array}$ & $\begin{array}{l}2.609 .63 \\
6\end{array}$ & 997 & $\begin{array}{l}38,2 \\
0\end{array}$ & $\begin{array}{l}3.360 .95 \\
2\end{array}$ & 1329 & $\begin{array}{l}39,5 \\
4\end{array}$ & $\begin{array}{l}3.921 .05 \\
2\end{array}$ & 1800 & $\begin{array}{l}45,9 \\
1\end{array}$ & $\begin{array}{l}4.655 .97 \\
2\end{array}$ & 2314 & $\begin{array}{l}49,7 \\
0\end{array}$ \\
\hline Total & $\begin{array}{l}5.119 .81 \\
3\end{array}$ & 2399 & $\begin{array}{l}46,8 \\
6\end{array}$ & $\begin{array}{l}6.344 .99 \\
6\end{array}$ & 3122 & $\begin{array}{l}49,2 \\
0\end{array}$ & $\begin{array}{l}7.434 .03 \\
3\end{array}$ & 4096 & $\begin{array}{l}55,1 \\
0\end{array}$ & $\begin{array}{l}8.560 .18 \\
2\end{array}$ & 5213 & $\begin{array}{l}60,9 \\
0\end{array}$ \\
\hline
\end{tabular}

FIGURA 6 - COEFICIENTE BRUTO DE MORTALIDADE POR CÂNCER DE MAMA (POR 100.000 MULHERES)DE MULHERES COM IDADE IGUAL E SUPERIOR A 50 anos, NAS REgiões de ESTUdo No ESTAdo de SÃo PaUlo, NoS TRIÊNIOS 1979-1981, 1984-1986, 1990-1992 E 1995-1997.

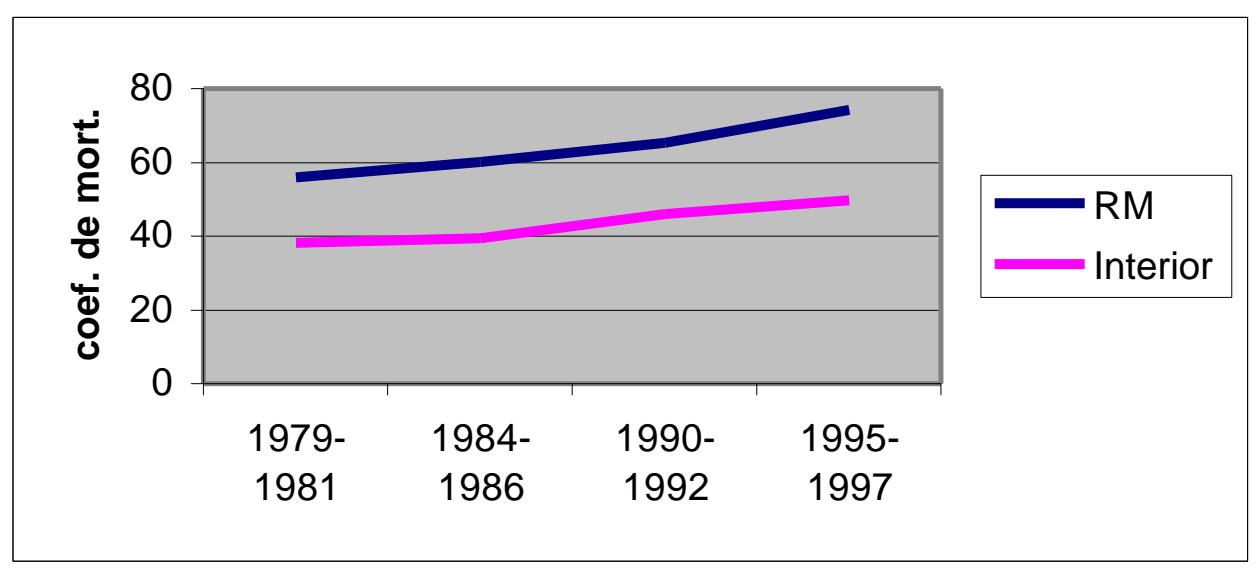


As TABELAS 7, 8, 9 e 10 e as FIGURAS 7, 8, 9 e 10 referem-se à mortalidade por câncer de mama de mulheres com idade igual e superior a 50 anos, nas regiões em estudo, segundo grupos etários e por triênio estudado.

TABELA 7 - NÚMERO DE ÓBITOS, COEFICIENTE DE MORTALIDADE POR CÂNCER DE MAMA DE MULHERES COM IDADE IGUAL E SUPERIOR A 50 ANOS (POR 100.000 MULHERES) SEGUNDO GRUPOS ETÁRIOS, NO TRIÊNIO 19791981, E POPUlaÇão FEMININA DE 1980, SEgundo AS REGIÕES DE ESTUDO NO ESTADO DE SÃO PAULO.

\begin{tabular}{|c|c|c|c|c|c|c|}
\hline \multirow{3}{*}{ Faixa Etária } & \multicolumn{6}{|c|}{ PRIMEIRO TRIÊNIO } \\
\hline & \multicolumn{3}{|c|}{ Região Metropolitana } & \multicolumn{3}{|c|}{ Interior } \\
\hline & $\mathbf{N}$ & População & Coef & $\mathbf{N}$ & População & Coef \\
\hline $50-54$ & 324 & 741047 & 43,72 & 201 & 744982 & 26,98 \\
\hline $55-59$ & 323 & 561411 & 57,53 & 236 & 562616 & 41,94 \\
\hline $60-64$ & 152 & 425122 & 35,75 & 122 & 451769 & 27,00 \\
\hline $65-69$ & 253 & 319085 & 79,28 & 191 & 363872 & 52,49 \\
\hline $70-74$ & 119 & 293347 & 40,56 & 85 & 293679 & 28,94 \\
\hline $75-79$ & 121 & 94169 & 128,49 & 99 & 107687 & 91,93 \\
\hline $80 \mathrm{e}+$ & 110 & 75996 & 144,74 & 63 & 85031 & 74,09 \\
\hline
\end{tabular}

FIGURA 7 - COEFICIENTE DE MORTALIDADE (POR 100.000 MULHERES) POR CÂNCER DE MAMA, SEgUNDO FAIXA ETÁRIA E REGIÕES DE ESTUdO NO ESTADO DE SÃO PAULO NO TRIÊNIO 1979-1981.

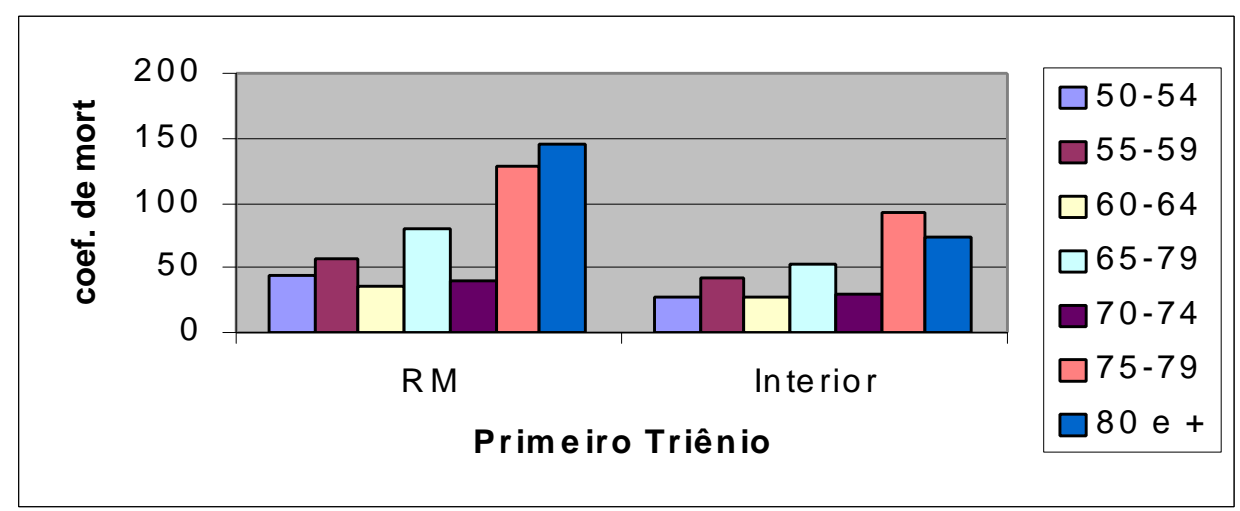


TABELA 8 - NUMERO DE ÓBITOS, COEFICIENTE DE MORTALIDADE POR CÂNCER DE MAMA (POR 100.000 MULHERES), SEGUNDO FAIXA ETÁRIA, NO TRIÊNIO 1984-1986, E POPULAÇÃo FEMININA DE 1980, SEGUNDO AS REGIÕES DE ESTUDO NO ESTADO DE SÃO PAULO.

\section{SEGUNDO TRIÊNIO}

\begin{tabular}{ccccccc} 
Faixa Etária & \multicolumn{3}{c}{ Região Metropolitana } & \multicolumn{3}{c}{ Interior } \\
& N & População & Coef & N & População & Coef \\
\hline $50-54$ & 298 & 824410 & 36,14 & 229 & 827005 & 27,69 \\
$55-59$ & 405 & 646182 & 62,67 & 303 & 710471 & 42,64 \\
$60-64$ & 266 & 529827 & 50,20 & 197 & 619372 & 31,80 \\
$65-69$ & 334 & 395802 & 84,38 & 229 & 468644 & 48,86 \\
$70-74$ & 182 & 263921 & 68,96 & 126 & 291511 & 43,22 \\
$75-79$ & 167 & 173836 & 96,06 & 153 & 232514 & 65,80 \\
80 e + & 141 & 150066 & 93,95 & 92 & 211435 & 43,51 \\
\hline
\end{tabular}

FIGURA 8 - COEFICIENTE DE MORTALIDADE (POR 100.000 MULHERES) POR CÂNCER DE MAMA, SEgUNDO FAIXA ETÁRIA E REgIÕES DE ESTUDO NO ESTADO DE SÃO PAULO NO TRIÊNIO 1984-1986.

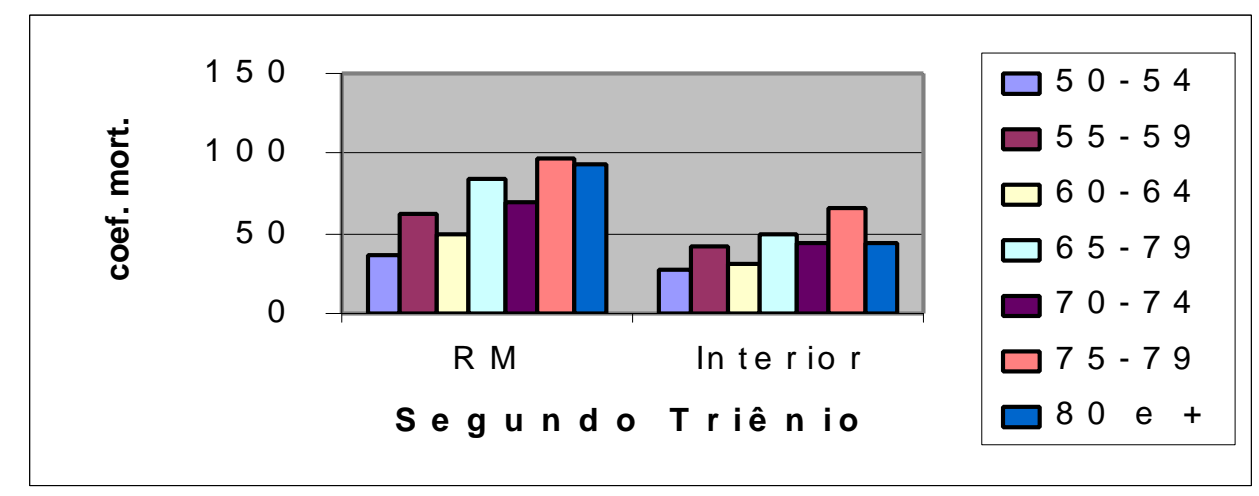


TABELA 9 - NUMERO DE ÓBITOS, COEFICIENTE DE MORTALIDADE POR CÂNCER DE MAMA (POR 100.000 MULHERES), SEGUNDO FAIXA ETÁRIA, NO TRIÊNIO 1990-1992, E POPULAÇÃo FEMININA dE 1991, SEGUNDO AS REGIÕES DE ESTUDO NO ESTADO DE SÃO PAULO.

\begin{tabular}{ccccccc}
\hline & \multicolumn{5}{c}{ TERCEIRO TRIÊNIO } \\
Faixa Etária & \multicolumn{7}{c}{ Região Metropolitana } & & Interior & \\
& N & População & Coef & N & População & Coef \\
\hline $50-54$ & 409 & 904646 & 45,21 & 300 & 940616 & 31,89 \\
$55-59$ & 481 & 742571 & 64,77 & 387 & 833087 & 46,45 \\
$60-64$ & 325 & 648958 & 50,08 & 244 & 732231 & 33,32 \\
$65-69$ & 389 & 481275 & 80,82 & 307 & 543261 & 56,51 \\
$70-74$ & 224 & 321904 & 69,58 & 174 & 373489 & 46,58 \\
$75-79$ & 264 & 215814 & 122,32 & 198 & 262195 & 75,51 \\
80 e + & 204 & 197813 & 103,12 & 190 & 236173 & 80,44 \\
\hline
\end{tabular}

FIGURA 9 - COEFICIENTE DE MORTALIDADE (POR 100.000 MULHERES) POR CÂNCER DE MAMA, SEgUNDO FAIXA ETÁRIA E REgIÕES DE ESTUdO NO ESTADO DE SÃO PAULO NO TRIÊNIO 1990-1992.

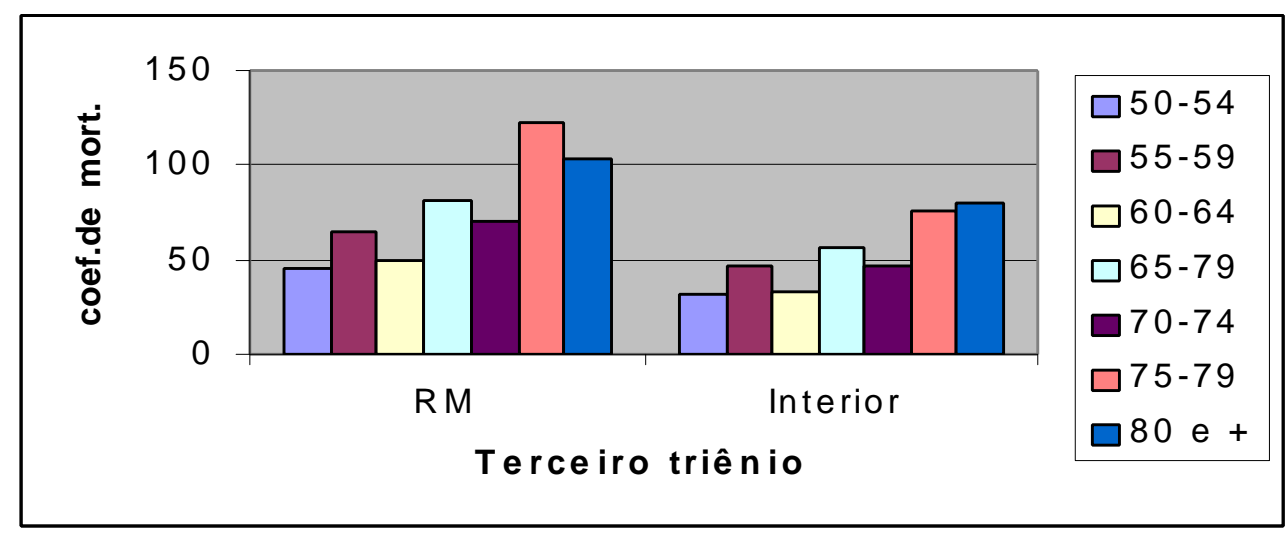


TABELA 10 - NUMERO DE ÓBITOS, COEFICIENTE DE MORTALIDADE POR CÂNCER DE MAMA (POR 100.000 MULHERES) DE MULHERES COM IDADE IGUAL E SUPERIOR A 50 ANOS, SEGUNDO GRUPOS ETÁRIOS, NO TRIÊNIO 19951997, E POPUlAÇÃo FEMININA dA CONTAGEM POPULACIONAL DE 1996, SEGUNDO AS REGIÕES DE ESTUDO NO ESTADO DE SÃO PAULO.

\begin{tabular}{cccc|ccc}
\hline & \multicolumn{6}{c}{ QUARTO TRIÊNIO } \\
Faixa Etária & \multicolumn{2}{c}{ Região Metropolitana } & \multicolumn{3}{c}{ Interior } \\
& N & População & Coef & N & População & Coef \\
\hline $50-54$ & 476 & 1011603 & 47,05 & 356 & 130009 & 31,50 \\
$55-59$ & 544 & 803670 & 67,69 & 450 & 925024 & 48,65 \\
$60-64$ & 394 & 689356 & 57,15 & 326 & 805390 & 40,48 \\
$65-69$ & 509 & 545981 & 93,23 & 431 & 683732 & 63,04 \\
$70-74$ & 278 & 378272 & 73,49 & 219 & 488282 & 44,85 \\
$75-79$ & 324 & 239682 & 135,18 & 267 & 306213 & 87,19 \\
80 e + & 350 & 235646 & 148,53 & 265 & 317322 & 83,51 \\
\hline
\end{tabular}

FIGURA 10 - COEFICIENTE DE MORTALIDADE (POR 100.000 MULHERES) POR CÂNCER DE MAMA, SEgUNDO GRUPOS ETÁRIOS A PARTIR DE 50 ANOS E REGIÕES DE ESTUdO NO ESTAdO DE SÃo PAULO NO TRIÊNIO 19951997.

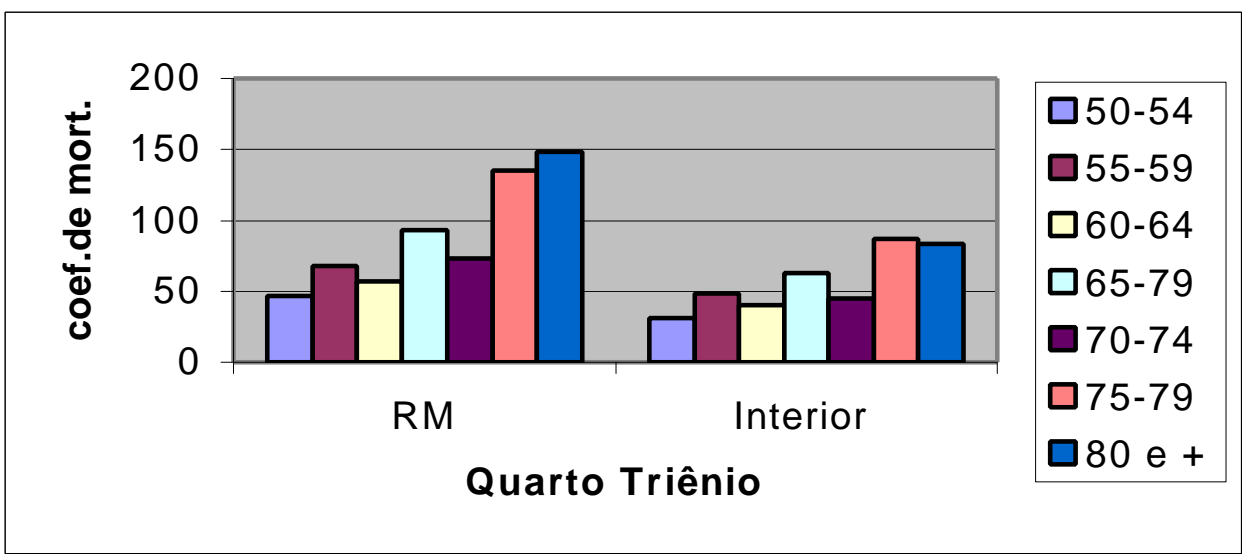


Observando a distribuição dos coeficientes de mortalidade nos triênios, por grupos etários e pelas regiões em estudo, verifica-se que os grupos que apresentaram menor oscilação dos coeficientes foram os de $75-79$ e 80 anos e mais, sendo que, no quarto triênio, a região metropolitana apresentou os maiores coeficientes - 135,18 e 148,53/100.000 mulheres, respectivamente, enquanto que, no interior de São Paulo ocorreu decréscimo, quando comparado com o primeiro triênio ( $1^{\circ}$ triênio $-91,93$ e 74,09/100.000 mulheres; $4^{\circ}$ triênio - 87,19 e 83,51/100.000 mulheres).

Os coeficientes de mortalidade por câncer de mama para o Estado de São Paulo (Região Metropolitana e Interior) podem ser vistos nas TABELAS 11 e 12 (FIGURAS 11 e 12). Foram padronizados pelas populações do Brasil - CENSO 1991 e mundial - 1991. 
TABELA 11 - COEFICIENTE BRUTO E PADRONIZADO DE MORTALIDADE POR CÂNCER DE MAMA DE MULHERES COM 50 ANOS E MAIS DE IDADE (POR 100.000 MULHERES E AJUSTADOS POR IDADE PELA POPULAÇÃo MUNDIAL), NO ESTADO DE SÃo PAULO, NOS TRIÊNIOS 1979-1981, 1984-1986, 19901992 E 1995-1997.

\begin{tabular}{l|c|c}
\hline Triênio & Coef. Bruto & Coef. Padronizado \\
\hline & & \\
$1979-81$ & 46,62 & 49,43 \\
$1984-86$ & 49,58 & 51,17 \\
$1990-92$ & 55,10 & 56,84 \\
$1995-97$ & 60,62 & 62,32 \\
& & \\
\hline
\end{tabular}

FIGURA 11 - COEFICIENTE BRUTO E PADRONIZADO DE MORTALIDADE POR CÂNCER DE MAMA DE MULHERES COM IDADE IGUAL E SUPERIOR A 50 ANOS (POR 100.000 MULHERES E AJUSTADOS POR IDADE PELA POPULAÇÃO mundial), no estado de são Paulo, no Período de 1979 A 1997,POR TRIÊNIO

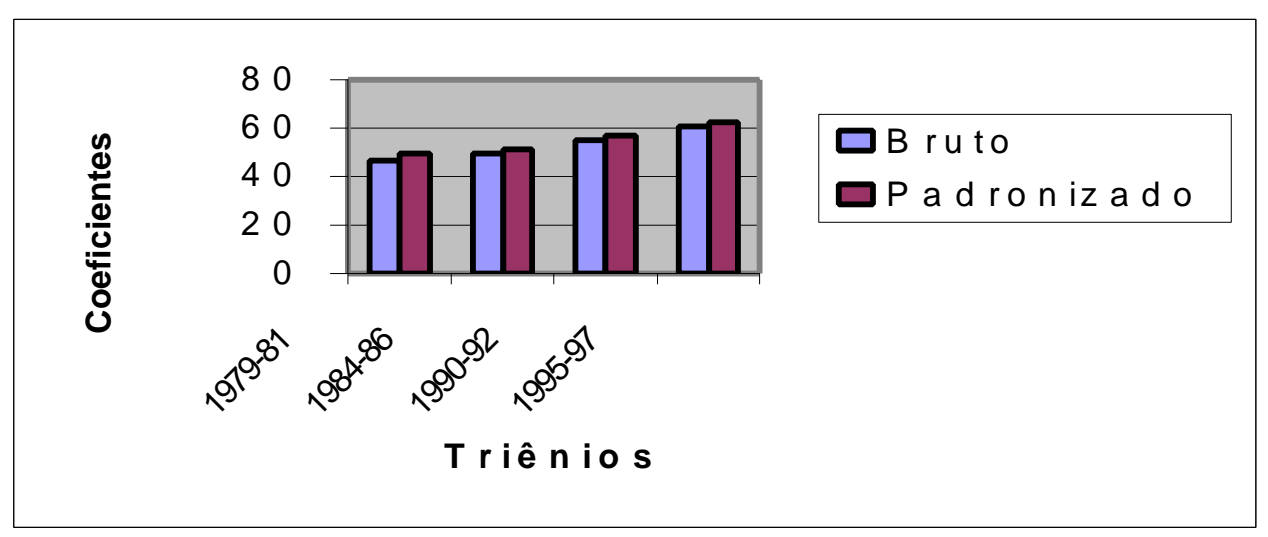


TABELA 12 - COEFICIENTE BRUTO E PADRONIZADO DE MORTALIDADE POR CÂNCER DE MAMA DE MULHERES COM IDADE IGUAL E SUPERIOR A 50 ANOS (POR 100.000 MULHERES E AJUSTADOS POR IDADE PELA POPULAÇÃo MUNDIAL - 1991), SEGUNDO AS REGIÕES DE ESTUDO, NO ESTADO DE SÃO PAULO, NOS TRIÊNIOS 1979-1981, 1984-1986, 1990-1992 E 19951997.

Triênios

\begin{tabular}{cccccccccc}
\hline Regiões & \multicolumn{2}{c}{$\mathbf{1 9 7 9 - 8 1}$} & \multicolumn{2}{c}{$\mathbf{1 9 8 4 - 8 6}$} & \multicolumn{2}{c}{$\mathbf{1 9 9 0 - 9 2}$} & \multicolumn{1}{c}{$\mathbf{1 9 9 5 - 9 7}$} \\
& $\begin{array}{c}\text { Coef. } \\
\text { Bruto }\end{array}$ & $\begin{array}{c}\text { Coef. } \\
\text { Pad. }\end{array}$ & $\begin{array}{c}\text { Coef. } \\
\text { Bruto }\end{array}$ & $\begin{array}{c}\text { Coef. } \\
\text { pad. }\end{array}$ & $\begin{array}{c}\text { Coef. } \\
\text { Bruto }\end{array}$ & $\begin{array}{c}\text { Coef. } \\
\text { Pad. }\end{array}$ & $\begin{array}{c}\text { Coef. } \\
\text { Bruto }\end{array}$ & $\begin{array}{c}\text { Coef. } \\
\text { Pad. }\end{array}$ \\
\hline RM & 55,85 & 64,03 & 60,09 & 63,17 & 65,36 & 67,91 & 74,25 & 76,74 \\
& & & & & & & & & \\
Interior & 38,20 & 42,43 & 39,54 & 40,17 & 45,91 & 47,11 & 49,70 & 50,63 \\
\hline
\end{tabular}

FIGURA 12 - COEFICIENTE BRUTO E PADRONIZADO DE MORTALIDADE POR CÂNCER DE MAMA DE MULHERES COM IDADE IGUAL E ACIMA DE 50 ANOS (POR 100.000 MUlheres E AJUSTAdos POR IDAde PELA POPUlaÇão MUNDIAL - 1991), SEGUNDO AS REGIÕES DE ESTUDO, NO ESTADO DE SÃO PAULO, NOS TRIÊNIOS 1979-1981, 1984-1986, 1990-1992 E 19951997.

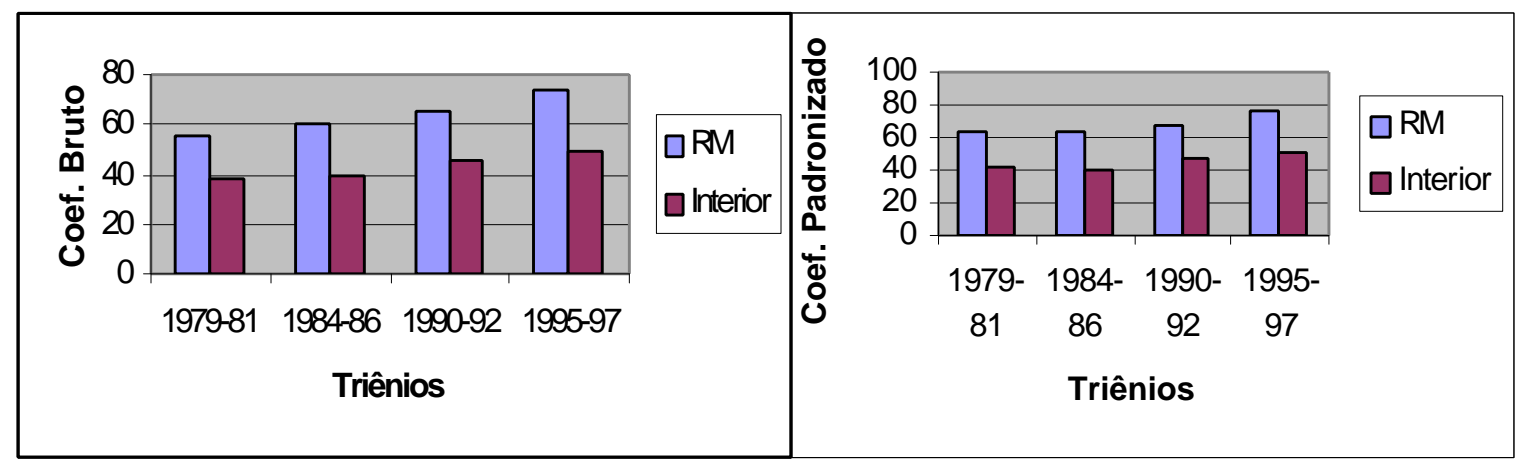


TABELA 13 - COEFICIENTE BRUTO E PADRONIZADO DE MORTALIDADE POR CÂNCER DE MAMA DE MULHERES COM IDADE IGUAL E ACIMA DE 50 ANOS (POR 100.000 MUlheres E AJUSTAdos POR IDAde PELA POPUlaÇÃo FEMININA DO BRASIL - CENSO 1991), NOS TRIÊNIOS 1979-1981, 19841986, 1990-1992 E 1995-1997.

\begin{tabular}{|c|c|c|c|c|c|c|c|c|}
\hline \multirow{3}{*}{ Regiões } & \multicolumn{6}{|c|}{ Triênios } & & \\
\hline & \multicolumn{2}{|c|}{ 1979-81 } & \multicolumn{2}{|c|}{ 1984-86 } & \multicolumn{2}{|c|}{ 1990-92 } & \multicolumn{2}{|c|}{ 1995-97 } \\
\hline & $\begin{array}{l}\text { Coef. } \\
\text { Bruto }\end{array}$ & $\begin{array}{l}\text { Coef. } \\
\text { Pad. }\end{array}$ & $\begin{array}{l}\text { Coef. } \\
\text { Bruto }\end{array}$ & $\begin{array}{l}\text { Coef. } \\
\text { Pad. }\end{array}$ & $\begin{array}{l}\text { Coef. } \\
\text { Bruto }\end{array}$ & $\begin{array}{l}\text { Coef. } \\
\text { Pad. }\end{array}$ & $\begin{array}{l}\text { Coef. } \\
\text { Bruto }\end{array}$ & $\begin{array}{l}\text { Coef. } \\
\text { Pad. }\end{array}$ \\
\hline $\mathrm{RM}$ & 55,85 & 59,36 & 60,09 & 62,50 & 65,36 & 66,61 & 74,25 & 74,26 \\
\hline Interior & 38,20 & 39,73 & 39,54 & 39,93 & 45,91 & 46,04 & 49,70 & 48,81 \\
\hline
\end{tabular}

FIGURA 13 - COEFICIENTE BRUTO E PADRONIZADO DE MORTALIDADE POR CÂNCER DE MAMA DE MULHERES COM IDADE IGUAL E ACIMA DE 50 ANOS (POR 100.000 MULheres E AJUSTAdos POR IDAde PELA POPUlaÇão FEMININA do BRASIL CENSO 1991), NOS TRIÊNIOS 1979-1981, 1984-1986, 1990-1992 E 1995-1997.

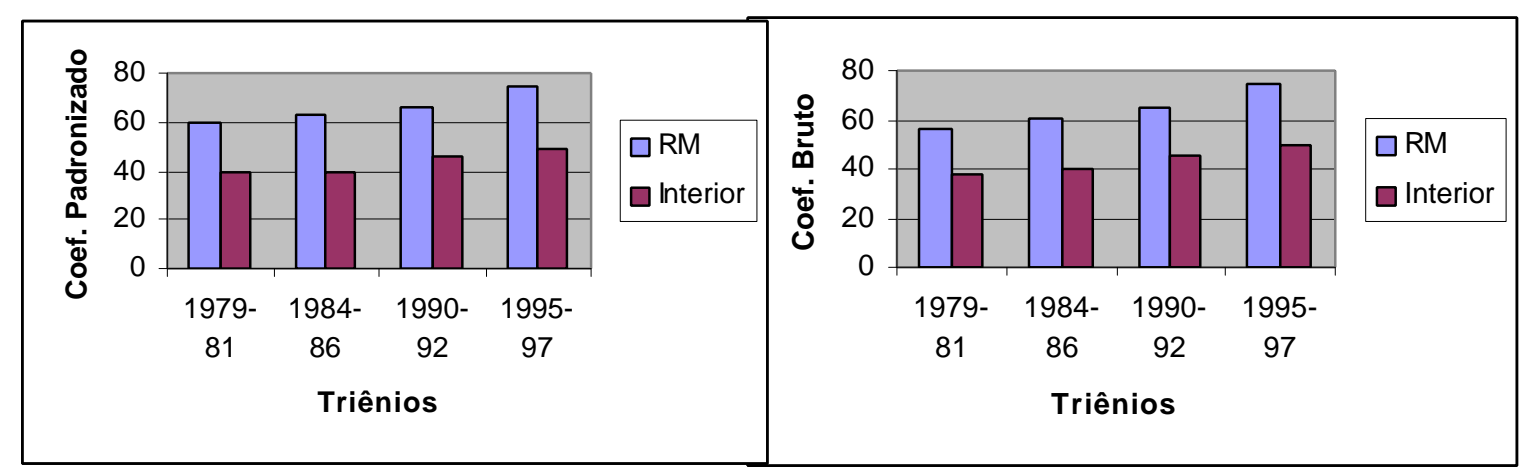


Comparando-se as taxas padronizadas por idade da população feminina do Estado de São Paulo, padronizada pela população feminina do Brasil em 1991, das regiões Metropolitana e interior, do primeiro para o quarto triênio, verifica-se um aumento de $22,85 \%$ e $26,67 \%$ nas taxas de mortalidade, respectivamente.

TABELA 14 - EVOLUÇÃO DA MORTALIDADE DE MULHERES COM IDADE IGUAL E SUPERIOR A 50 ANOS, NA REGIÃO METROPOLITANA, NOS TRIÊNIOS (1979-1981, 1984--1986, 1990-1992, 1995-1997).

\begin{tabular}{c|r|r|r|r|r}
\hline $\begin{array}{c}\text { Grupo } \\
\text { Etário }\end{array}$ & $\mathbf{1}^{\mathbf{0}}$. Triênio & $\mathbf{2}^{\mathbf{0}}$. Triênio & $\mathbf{3}^{\mathbf{0}}$. Triênio & $\mathbf{4}^{\mathbf{0}}$. Triênio & Total \\
\hline 50-54 anos & 43,72 & 36,14 & 45,21 & 47,05 & $\mathbf{1 7 2 , 1 2}$ \\
$55-59$ anos & 57,53 & 62,67 & 64,77 & 64,69 & $\mathbf{2 4 9 , 6 6}$ \\
$60-64$ anos & 35,75 & 50,20 & 50,08 & 57,15 & $\mathbf{1 9 3 , 1 8}$ \\
$65-69$ anos & 79,28 & 84,38 & 80,82 & 93,23 & $\mathbf{3 3 7 , 7 1}$ \\
$70-74$ anos & 40,56 & 68,96 & 69,58 & 73,49 & $\mathbf{2 5 2 , 5 9}$ \\
$75-79$ anos & 128,49 & 96,06 & 122,22 & 135,18 & $\mathbf{4 8 1 , 9 5}$ \\
80 e + & 144,74 & 93,95 & 103,12 & 148,53 & $\mathbf{4 9 0 , 3 4}$ \\
\hline Total & $\mathbf{5 3 0 , 0 7}$ & $\mathbf{4 9 2 , 3 6}$ & $\mathbf{5 3 5 , 8 0}$ & $\mathbf{6 1 9 , 3 2}$ & $\mathbf{2 1 7 7 , 5 5}$ \\
\hline
\end{tabular}

FigURA 14 - EVOLUÇÃO DA MORTALIDADE DE MULHERES COM IDADE IGUAL E SUPERIOR A 50 ANOS, NA REGIÃO METROPOLITANA, NOS TRIÊNIOS (1979-1981, 1984-1986, 1990-1992, 1995-1997).

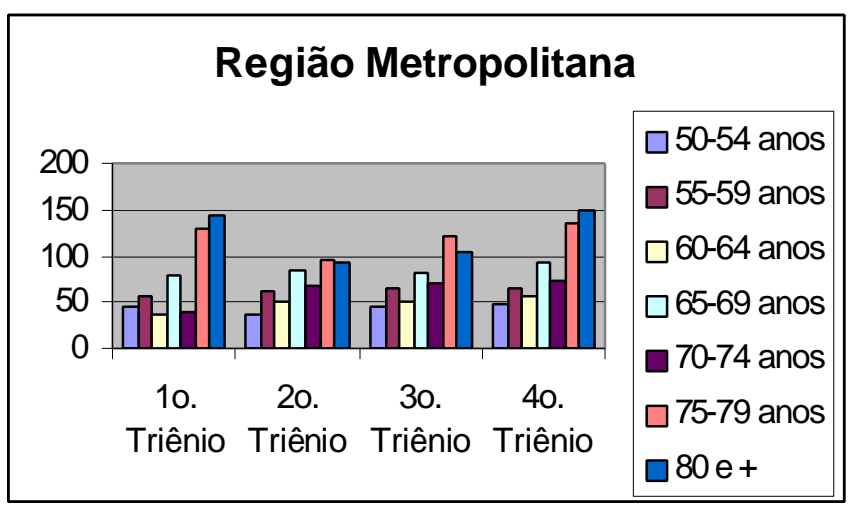


TABELA 15 - EVOLUÇÃo DA MORTALIDADE DE MULHERES COM IDADE IGUAL E SUPERIOR A 50 ANOS, NO INTERIOR DE SÃO PAULO, NOS TRIÊNIOS (1979-1981, 1984-1986, 1990-1992, 1995-1997).

\begin{tabular}{c|r|r|r|r|r}
\hline $\begin{array}{l}\text { Grupo } \\
\text { Etário }\end{array}$ & $\mathbf{1}^{\mathbf{0}}$. Triênio & $\mathbf{2}^{\mathbf{0}}$. Triênio & $\mathbf{3}^{\mathbf{0}}$. Triênio & $\mathbf{4}^{\mathbf{0}}$. Triênio & \multicolumn{1}{c}{ Total } \\
\hline 50-54 anos & 26,98 & 27,69 & 31,89 & 31,50 & $\mathbf{1 1 8 , 0 6}$ \\
$55-59$ anos & 41,94 & 42,64 & 46,45 & 48,65 & $\mathbf{1 7 9 , 6 8}$ \\
$60-64$ anos & 27,00 & 31,80 & 33,32 & 40,48 & $\mathbf{1 3 2 , 6 0}$ \\
$65-69$ anos & 52,49 & 48,96 & 56,51 & 63,04 & $\mathbf{2 2 1 , 0 0}$ \\
$70-74$ anos & 28,94 & 43,22 & 46,58 & 44,85 & $\mathbf{1 6 3 , 5 9}$ \\
$75-79$ anos & 91,93 & 65,80 & 75,51 & 87,19 & $\mathbf{3 2 0 , 4 3}$ \\
80 e + & 74,09 & 43,51 & 80,44 & 83,51 & $\mathbf{2 8 1 , 5 5}$ \\
\hline Total & $\mathbf{3 4 3 , 3 7}$ & $\mathbf{3 0 3 , 6 2}$ & $\mathbf{3 7 0 , 7 0}$ & $\mathbf{3 9 9 , 2 2}$ & $\mathbf{1 4 1 6 , 9 1}$ \\
\hline \multicolumn{7}{r}{}
\end{tabular}

Figura 15 - EVOLUÇÃo dA MORTALIDAdE DE MULHERES COM IDADE IGUAL E SUPERIOR A 50 ANOS, NO INTERIOR DE SÃO PAULO, NOS TRIÊNIOS (1979-1981, 1984-1986, 1990-1992, 1995-1997).

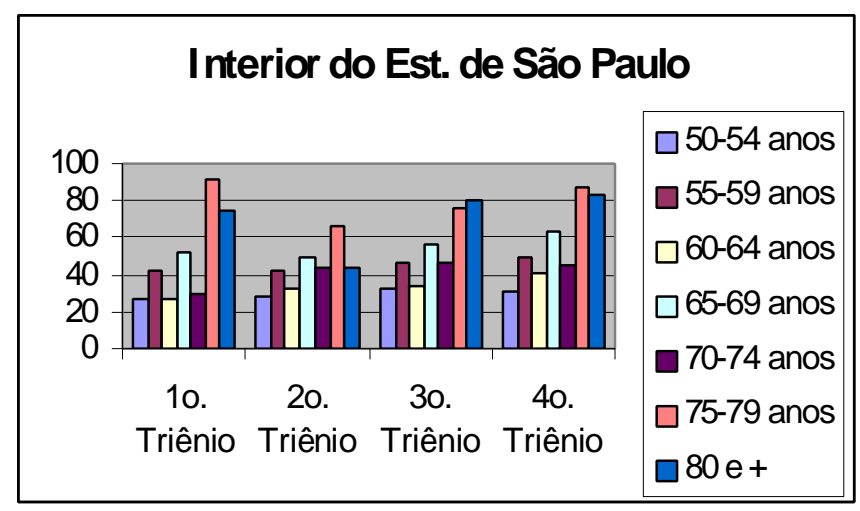


TABELA 16 - EVOLUÇÃo DA MORTALIDADE DE MULHERES COM IDADE IGUAL E SUPERIOR A 50 ANOS, NO ESTADO DE SÃO PAULO, NOS TRIÊNIOS (1979-1981, 1984-1986, 1990-1992, 1995-1997).

\begin{tabular}{c|r|r|r|r|r}
\hline $\begin{array}{l}\text { Grupo } \\
\text { Etário }\end{array}$ & $\mathbf{1}^{\mathbf{0}}$. Triênio & $\mathbf{2}^{\mathbf{0}}$. Triênio & $\mathbf{3}^{\mathbf{0}}$. Triênio & $\mathbf{4}^{\mathbf{0}}$. Triênio & \multicolumn{1}{c}{ Total } \\
\hline 50-54 anos & 35,33 & 31,91 & 38,42 & 38,85 & $\mathbf{1 4 4 , 5 1}$ \\
$55-59$ anos & 49,73 & 52,19 & 55,09 & 57,5 & $\mathbf{2 1 4 , 5 1}$ \\
$60-64$ anos & 31,25 & 40,29 & 41,2 & 48,17 & $\mathbf{1 6 0 , 9 1}$ \\
$65-69$ anos & 65,01 & 65,13 & 67,93 & 76,44 & $\mathbf{2 7 4 , 5 1}$ \\
$70-74$ anos & 53,99 & 55,45 & 57,23 & 57,35 & $\mathbf{2 2 4 , 0 2}$ \\
$75-79$ anos & 73,32 & 78,75 & 96,65 & 108,26 & $\mathbf{3 5 6 , 9 8}$ \\
80 e + & 73,28 & 71,09 & 90,79 & 111,22 & $\mathbf{3 4 6 , 3 8}$ \\
\hline Total & $\mathbf{3 8 1 , 9 1}$ & $\mathbf{3 9 4 , 8 1}$ & $\mathbf{4 4 7 , 3 1}$ & $\mathbf{4 9 7 , 7 9}$ & $\mathbf{1 7 2 1 , 8 2}$ \\
\hline
\end{tabular}

FigurA 16 - EVOLUÇÃO DA MORTALIDADE DE MULHERES COM IDADE IGUAL E SUPERIOR A 50 ANOS, NO ESTADO DE SÃO PAULO, NOS TRIÊNIOS (1979-1981, 19841986, 1990-1992, 1995-1997).

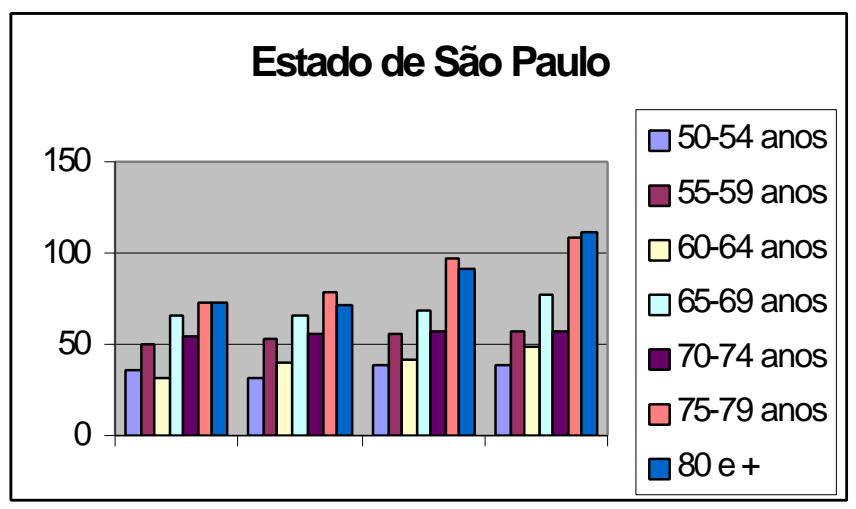


TABELA 17 - GRUPOS ETÁRIOS QUE APRESENTARAM OS MAIORES COEFICIENTES DE MORTALIDADE POR CÂNCER DE MAMA EM MULHERES COM IDADE IGUAL E SUPERIOR A 50 ANOS, NA REGIÃO METROPOLITANA, NOS TRIÊNIOS (1979-1981, 1984-1986, 1990-1992, 1995-1997).

\begin{tabular}{c|r|r|r|r|r}
\hline $\begin{array}{c}\text { Grupo } \\
\text { Etário }\end{array}$ & $1^{0}$. Triênio & $2^{0}$. Triênio & $3^{0}$. Triênio & $4^{0}$. Triênio & \multicolumn{1}{|c}{ Total } \\
\hline $55-59$ anos & 57,53 & 62,67 & 64,77 & 64,69 & 249,66 \\
$65-69$ anos & 79,28 & 84,38 & 80,82 & 93,23 & 337,71 \\
$75-79$ anos & 128,49 & 96,06 & 122,22 & 135,18 & 481,95 \\
80 e + & 144,74 & 93,95 & 103,12 & 148,53 & 490,34 \\
\hline Total & 410,04 & 337,06 & 370,93 & 441,63 & 1559,66 \\
\hline
\end{tabular}

FIGURA 17 - GRUPOS ETÁRIOS QUE APRESENTARAM OS MAIORES COEFICIENTES DE MORTALIDADE POR CÂNCER DE MAMA EM MULHERES COM IDADE IGUAL E SUPERIOR A 50 ANOS, NA REGIÃO METROPOLITANA, NOS TRIÊNIOS (1979-1981, 1984-1986, 1990-1992, 1995-1997).

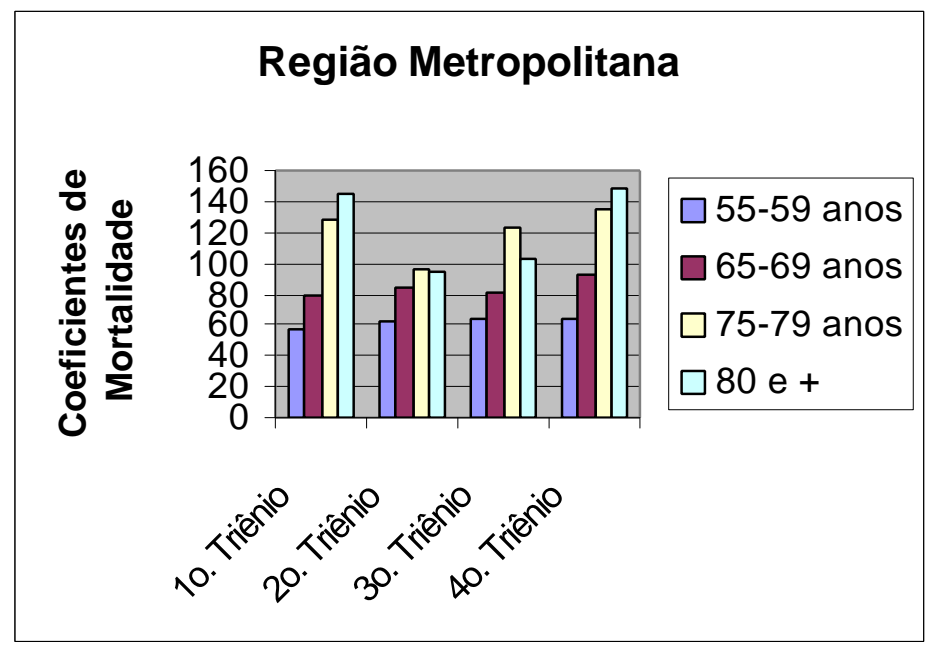


TABELA 18 - GRUPOS ETÁRIOS QUE APRESENTARAM OS MAIORES COEFICIENTES DE MORTALIDADE POR CÂNCER DE MAMA EM MULHERES COM IDADE IGUAL E SUPERIOR A 50 ANOS, NO INTERIOR DE SÃO PAULO, NOS TRIÊNIOS (1979-1981, 1984-1986, 1990-1992, 1995-1997).

\begin{tabular}{c|r|r|r|r|r}
\hline $\begin{array}{c}\text { Grupo } \\
\text { Etário }\end{array}$ & $1^{0}$. Triênio & $2^{0}$. Triênio & $3^{0}$. Triênio & $4^{0}$. Triênio & \multicolumn{1}{|c}{ Total } \\
\hline $55-59$ anos & 41,94 & 42,64 & 46,45 & 48,65 & 179,68 \\
$65-69$ anos & 52,49 & 48,96 & 56,51 & 63,04 & 221,00 \\
$75-79$ anos & 91,93 & 65,80 & 75,51 & 87,19 & 320,43 \\
80 e + & 74,09 & 43,51 & 80,44 & 83,51 & 281,55 \\
\hline Total & 260,45 & 200,91 & 258,91 & 282,39 & 1002,66 \\
\hline
\end{tabular}

FIGURA 18 - GRUPOS ETÁRIOS QUE APRESENTARAM OS MAIORES COEFICIENTES DE MORTALIDADE POR CÂNCER DE MAMA EM MULHERES COM IDADE IGUAL E SUPERIOR A 50 ANOS, NO INTERIOR DE SÃo PAULO, NOS TRIÊNIOS (1979-1981, 1984-1986, 1990-1992, 1995-1997).

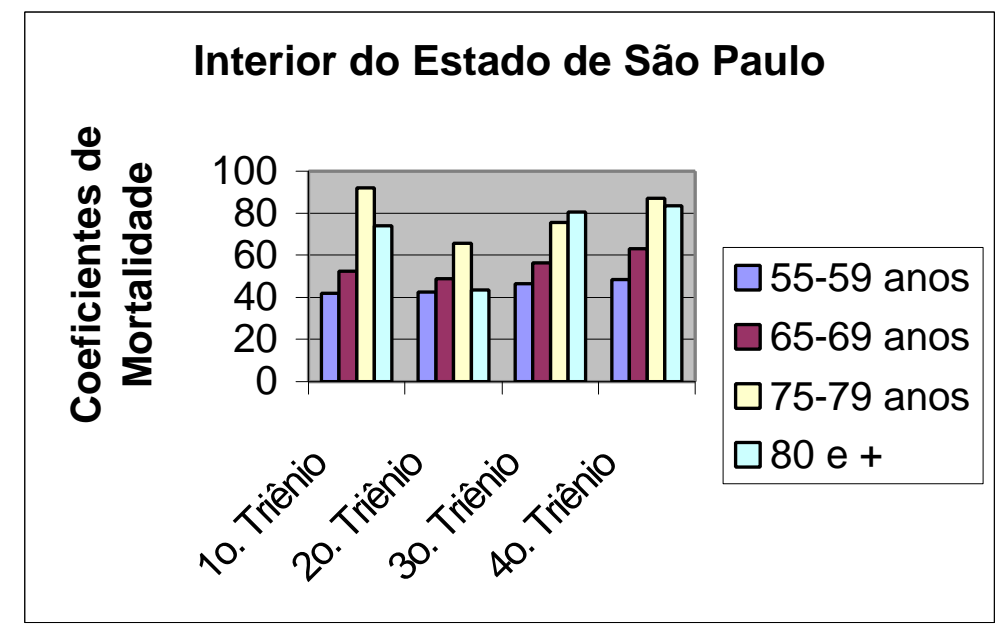


TABELA 19 - GRUPOS ETÁRIOS QUE APRESENTARAM OS MAIORES COEFICIENTES DE MORTALIDADE POR CÂNCER DE MAMA EM MULHERES COM IDADE IGUAL E SUPERIOR A 50 ANOS, NO ESTADO DE SÃo PAULO, NOS TRIÊNIOS (1979-1981, 1984-1986, 1990-1992, 1995-1997).

\begin{tabular}{c|r|r|r|r|r}
\hline $\begin{array}{c}\text { Grupo } \\
\text { Etário }\end{array}$ & $1^{0}$. Triênio & $2^{0}$. Triênio & $3^{0}$. Triênio & $4^{0}$. Triênio & \multicolumn{1}{|c}{ Total } \\
\hline $55-59$ anos & 49,73 & 52,19 & 55,09 & 57,5 & 214,51 \\
$65-69$ anos & 65,01 & 65,13 & 67,93 & 76,44 & 274,51 \\
$75-79$ anos & 73,32 & 78,75 & 96,65 & 108,26 & 356,98 \\
80 e + & 73,28 & 71,09 & 90,79 & 111,22 & 346,38 \\
\hline Total & 261,34 & 267,16 & 310,46 & 353,42 & 1192,38 \\
\hline
\end{tabular}

FIGURA 19 - GRUPOS ETÁRIOS QUE APRESENTARAM OS MAIORES COEFICIENTES DE MORTALIDADE POR CÂNCER DE MAMA EM MULHERES COM IDADE IGUAL E SUPERIOR A 50 ANOS, NO ESTAdo de SÃo PAUlO, NOS TRIÊNIOS (1979-1981, 1984-1986, 1990-1992, 1995-1997).

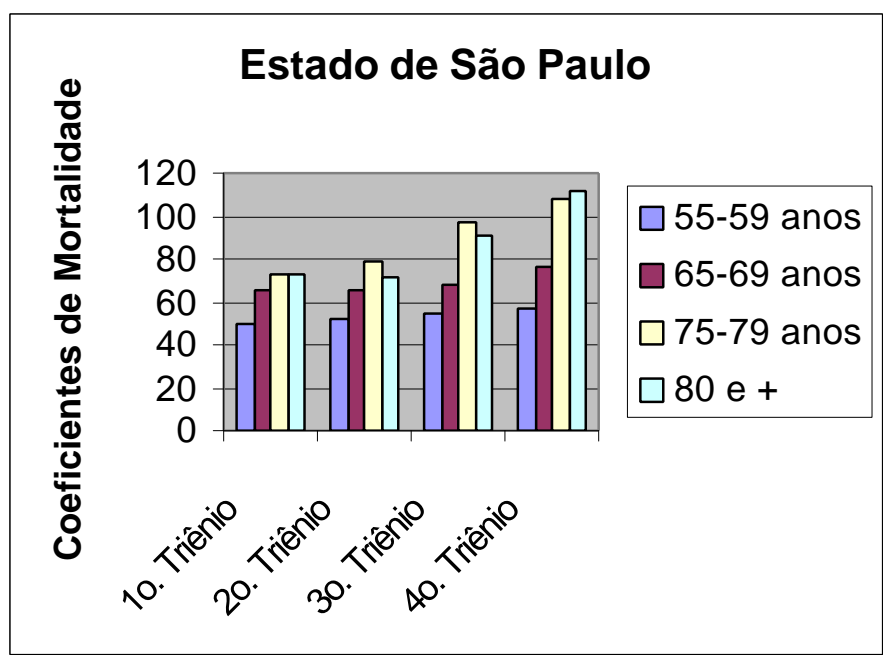


FIGURA 20 - GRUPOS ETÁRIOS QUE APRESENTARAM OS MAIORES COEFICIENTES DE MORTALIDADE POR CÂNCER DE MAMA EM MULHERES COM IDADE IGUAL E SUPERIOR A 50 ANOS, NO ESTAdO DE SÃO PAULO, REGIÃo METROPOLITANA E INTERIOR DE SÃO PAULO, NOS TRIÊNIOS (19791981, 1984-1986, 1990-1992, 1995-1997).
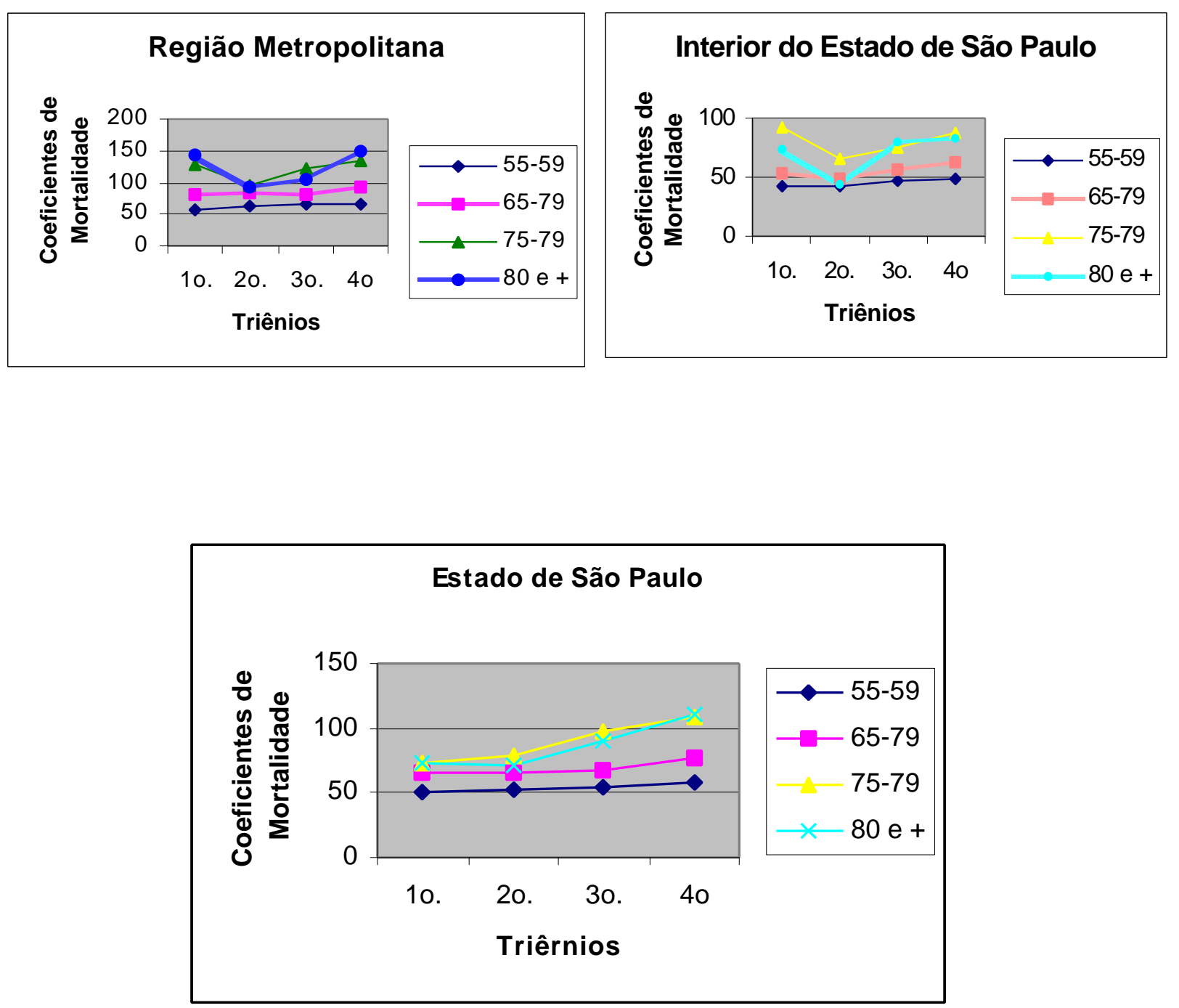


\section{DISCUSSÃO}

Antes de iniciarmos a discussão sobre os resultados encontrados em nosso estudo, vale assinalar alguns cuidados metodológicos que o estudo retrospectivo, com base em dados secundários, requer serem tomados, tais como:

- contornar problemas de flutuações - variação de ano/ano - por essa razão, optamos pelo agrupamento trienal, trabalhando com valores médios no período compreendido entre 1979 a 1997;

- controlar possíveis diferenças nas estruturas etárias entre populações de áreas de estudo - daí termos padronizado os coeficientes de mortalidade, tomando como padrão a população total do Estado de São Paulo, obtida pelo censo de 1991; ainda, para possíveis comparações com resultados de outros trabalhos internacionais, os coeficientes foram padronizados, também, segundo a população mundial, de 1991.

Com esses cuidados, foi realizado o presente estudo, cujos resultados discutimos neste capítulo.

O resultado encontrado para Estado de São Paulo foi de aumento no número de óbitos, por câncer de mama, de mulheres com idade igual e superior a 50 anos, no período estudado, com maior contribuição percentual do quarto triênio, da ordem de 35\%. Essa constatação vem confirmar o relatado na literatura, tanto nacional (DE LUCA, 1998; PINOTTI e TEIXEIRA, 2000), como internacional (HENDERSON,1993; KATZ, 1997; FORBES, 1997;SHAPIRO,1998; GOTZCHEL e OLSEN,2000; HEIMANN,2000), que assinala que nas últimas décadas, o câncer de mama tem se mostrado um dos maiores desafios em Saúde Pública em países 
desenvolvidos e em muitos em desenvolvimento, constituindo, dentre os cânceres, a primeira causa de óbito feminino do grupo etário de 50 anos e mais.

No Brasil, constata-se aumento da incidência, principalmente na região Sudeste. Este tem sido gradual e a taxa de sobrevida em dez anos não tem apresentado alteração, conforme dados do Ministério da Saúde, 1998.

Outro resultado encontrado neste estudo diz respeito à distribuição da mortalidade por câncer de mama de mulheres com idade igual e superior a 50 anos, segundo regiões consideradas desenvolvidas e regiões em desenvolvimento, no caso, entre Região Metropolitana e Interior do Estado. Os resultados revelam as maiores taxas de mortalidade feminina, por câncer de mama, na faixa etária estudada, localizadas na Região Metropolitana, em todos os triênios, com variação percentual média de 17\%; um aumento na taxa bruta de mortalidade correspondente de 32,95\% na Região Metropolitana e de 30,15 \% no Interior; um coeficiente de mortalidade por câncer de mama aumentado, tanto na Região Metropolitana, como no Interior, porém com valores maior na primeira. A literatura refere que, tanto a incidência, como a mortalidade por essa afecção são mais encontrados e, com valores mais elevados em regiões e estratos sócio-econômicos considerados desenvolvidos, o que pode estar corroborando com nossos resultados ( GOTLIEB, 1970; FORBES, 1997; DE LUCA, 1998; PINOTTI e TEIXEIRA, 2000).

Outro dado que é relatado na literatura, e que é confirmado em nosso estudo, refere-se à ocorrência de óbitos por câncer de mama aumentado à medida que 
avança a idade ${ }^{1}$ (HENDERSON, 1993; KATZ, 1997; SHAPIRO, 1998; GOTZCHE e OLSEN,2000).

Entretanto, em nosso estudo, verificamos que essa tendência de aumento não ocorreu às custas de um aumento uniforme em todos os grupos etários compreendidos, constatando-se oscilações entre eles. Assim é que o maior aumento significativo em termos percentuais foi observado no grupo etário de 55-59 anos, em todos os triênios; em termos de coeficientes de mortalidade por câncer de mama em mulheres de 50 anos e mais, o grupo etário de 75- 79 anos foi o que apresentou os maiores valores, com exceção no quarto triênio, em que o grupo de 80 anos e mais foi o que apresentou os maiores valores. De qualquer forma, o grupo de 75 anos e mais apresentou um crescimento de $47,65 \%$ entre o primeiro e o último triênio, valor este que se aproxima daquele encontrado nos EUA, em termos de incidência (40\%) de câncer de mama em mulheres acima de 50 anos. Certamente, em termos de incidência, a realidade do Estado de São Paulo deve apresentar uma proporção bem mais elevada, porém esta questão foge aos propósitos de nosso estudo. Da mesma forma, se a mortalidade de mulheres com idade igual e superior a 50 anos, por câncer de mama, no Estado de São Paulo, cresceu, em seu conjunto, cerca de $30 \%$, no período estudado, nos EUA, para o período de 1991-95, verificou-se um decréscimo de 4,6 \% na mortalidade. Este fato - decréscimo na mortalidade - tem sido atribuído à detecção mamográfica precoce, graças à expansão dos programas de screening, ao diagnóstico precoce e às intervenções eficazes sobre as lesões pré-

\footnotetext{
${ }^{1}$ Embora o presente estudo se refira à mortalidade por câncer de mama de mulheres com idade igual e superior a 50 anos, é importante reconhecer que essa doença vem ocorrendo em idades mais precoces, porém, por não constituir objeto deste estudo, fica apenas registrado que essa ocorrência em idades mais jovens se deva, provavelmente às modificações de vida da mulher moderna, ou seja, maior número de ciclos menstruais, em decorrência de menarca mais precoce e menopausa mais tardia;
} 
malignas realizadas regularmente naquele país. No entanto, em nosso entender, decréscimos na mortalidade não podem ser atribuídos somente ao rastreamento pela mamografia.

Importantes estudos canadenses, de GOTZSCHE e OLSEN (2000), concordam com os efeitos benéficos do rastreamento mamário por mamografia e exame físico realizado por médico ou enfermeiro. Estes estudos demonstraram que a mamografia realizada a cada 1-2 anos pode salvar vidas de mulheres com idade acima de 50 anos.

De qualquer forma, estudos revelam que programas de rastreamento, que incluem exame físico da mama por profissionais de saúde treinados, auto-exame de mama e mamografia, podem reduzir a mortalidade de câncer de mama em 30\%. O exame físico isolado pode identificar $2 / 3$ dos canceres detectados por mamografia.

Na maioria dos países, entretanto, as estratégias sanitárias implementadas no sentido de diminuir a mortalidade por esta neoplasia têm-se limitado ao estabelecimento de rastreamento com mamografia e ao incentivo para o auto-exame de mama, de forma a aumentar as chances de detecção precoce do câncer. No entanto, o impacto dos rastreamentos com mamografia sobre a mortalidade por câncer de mama tem suscitado algumas controvérsias: há indícios de que o screening não afetaria a taxa de mortalidade pela doença (UK TRIAL, 1988; MILLER 1992). Outros estudos, apontam para uma diminuição da taxa de mortalidade, a qual estaria relacionada a faixas etária específicas (STARREVELD, 1992; QUINN, 1995, MICHAELSON, 2000), particularmente a das mulheres com mais de 50 anos. Para BASINSKI, 1992, programas de rastreamento com mamografia só terão impacto 
sobre a mortalidade quando viabilizarem encaminhamento ágil para biópsias, disponibilidade de estratégias terapêuticas adequadas, mamografias de boa qualidade e leitura fidedigna. Vale lembrar que os padrões mamográficos são influenciados pela idade, peso corpóreo, e por fatores étnicos e reprodutivos, assim como podem ter sua precisão aumentada por uma segunda leitura radiológica (MILLER, 1992; KONING, 2000).

A implementação de estratégias para o diagnóstico precoce do câncer de mama não se constitui em tarefa fácil, pois sabe-se que a mamografia não viabiliza o diagnóstico preciso de malignidade em uma imagem radiologicamente suspeita de câncer de mama. Mesmo imagens suspeitas detectadas por exames tomográficos, por ressonância magnética ou por mamografia de alta resolução, demandam exames complementares, como biópsias mamárias, para confirmação diagnóstica.

Por outro lado, a decisão de submeter-se ao exame mamográfico, não depende apenas da disponibilidade do exame, sendo influenciado por vários outros fatores (SKINNER, 1994; MICKEY, 1995; SUTTON, 1995). Estes são, na sua maioria, altamente subjetivos e nem sempre controláveis, seja pelas autoridades sanitárias, pelos médicos ou, até, pelas próprias mulheres. Já o auto-exame não tem se mostrado um método tão efetivo na detecção precoce do câncer de mama e, portanto, não deve ser promovido como um procedimento primário de screening (AUSTOKER, 1994; NEWCOMB e col., 1995; PINOTTI e TEIXEIRA, 2000). Porém, apesar das dificuldades relacionadas à implementação de programas para o diagnóstico precoce do câncer de mama, alguns países, como o Reino Unido (QUINN,1995), Canadá (BASINSKI, 1992; GOTZSCHE e OLSEN, 2000), e 
Austrália (RODGER, 1995), têm obtido resultados avaliados como satisfatórios em relação às atividades programáticas ali desenvolvidas.

Ao se compararem os dados encontrados com os de países desenvolvidos, observam-se semelhanças quanto às elevadas taxas de mortalidade por câncer de mama, mas não na consecução de medidas necessárias à prevenção, diagnóstico precoce e controle da doença. Através da revisão bibliográfica sobre os fatores de risco desta afecção, pode-se pensar em forte relação desses fatores com as diferenças sócio-econômicas regionais e entre classes sociais, além de importantes mudanças nos hábitos de vida das mulheres.

Pode-se admitir que o padrão de mortalidade por câncer de mama no Estado de São Paulo, desde a década de 80, revela a existência de problemas de saúde de uma população formada por estratos distintos, e não de uma população homogênea; tais estratos apresentariam problemas específico e inerentes a cada segmento, onde coexistiriam condições típicas adversas à saúde. O padrão encontrado neste estudo, ora é de regiões consideradas desenvolvidas e com recursos e instrumentos de saúde em disponibilidade, ora de regiões em desenvolvimento e com medidas preventivas e/ou curativas precárias, quando disponíveis. Em nosso caso, as diferenças encontradas entre Região Metropolitana e Interior, como já foi dito, pode reforçar esse tipo de análise. Ao mesmo tempo, o fato de o grupo etário 55-59 anos apresentar os maiores coeficientes de mortalidade por esta neoplasia, pode estar refletindo o que foi até aqui relatado, a respeito da força de programas de rastreamento, largamente realizados em países desenvolvidos, porém quase inexistentes/ insuficientes/insatisfatórios em nosso meio. Isto é, esse grupo etário pode estar refletindo em seus coeficientes a não detecção precoce dessa afecção. 
Quanto às elevadas taxas de mortalidade encontradas nos grupos etários de 75 anos e mais, contrariando resultados de outros estudos internacionais que apresentam a tendência de declínio nessas idades ( HENDERSON, 1993; GOTZSCHE \& OLSEN,2000), fica a indagação sobre os fatores que estariam contribuindo para esse aumento, no Estado de São Paulo.

Em função do baixo grau de conscientização da população feminina, dos médicos e dos serviços assistenciais, $60 \%$ dos canceres são diagnosticados tardiamente (INCA, PRO-ONCO, 1998). E, na rede pública de serviços de saúde, o que existe em relação ao rastreamento, detecção e diagnóstico precoce do câncer de mama, em mulheres com idade igual e superior a 50 anos, localiza-se sobretudo em serviços ambulatoriais especializados: Ambulatórios de Atenção à Mulher no Climatério; em alguns hospitais, notadamente, os voltados ao ensino, refletindo o pouco que tem sido feito no sentido de desenvolvimento de ações de saúde voltadas a esse grupo de mulheres, não obstante contar-se com as denominadas ações básicas de Assistência Integral à Saúde da Mulher (ALDRIGHI e col., 1999).

A extensão deste trabalho limita-se à discussão dos problemas de saúde das mulheres acima de 50 anos, embora esta população precise mais do que apenas cuidado médico acessível. Além disso, o sistema de saúde atual é com freqüência mal preparado para trabalhar os problemas de saúde, incluindo os canceres de modo geral. Instituições formais como seguro social, pensões e seguro médico não oferecem apoio financeiro suficiente às pessoas deste segmento etário e na realidade cobrem um pequeno segmento da população. Assim, torna-se necessário estabelecer ou ampliar sistemas de serviços sociais para se alcançar um nível mínimo de bemestar. Como a maioria dos serviços de saúde para as mulheres são principalmente 
direcionados à gravidez e ao nascimento, eles não abordam todas as necessidades primárias de saúde das mulheres, mormente em grupos etários mais avançados. Os serviços freqüentemente são inacessíveis às populações rurais ou insuficientes para os moradores urbanos, e de qualidade inadequada.

Como o Brasil passa por uma rápida transição demográfica nos perfis de saúde, cresce a importância da necessidade da quantificação dos recursos apropriados, com que a sociedade tem que arcar, para fazer frente às necessidades específicas deste segmento etário. Uma das principais conseqüências dessa transformação demográfica é a demanda de redirecionamento de investimentos do setor saúde, a partir do redirecionamento das políticas públicas de saúde, voltadas para o atendimento das necessidades emergentes .

Estudos populacionais realizados em São Paulo têm demostrado que o aumento da sobrevida da mulher tem acarretado um aumento da prevalência de doenças crônicas, perda da independência funcional e da autonomia (ABREU, 1999). O aumento significativo no número de mulheres com mais de 50 anos em nosso país e uma participação desproporcional deste segmento etário na demanda por serviços de saúde justifica esta necessidade (INCA, 1977; ABREU, 1999). Taxas de condições crônicas em elevação, não somente o câncer de mama, mas doenças cardíacas e diabetes, requerem a adoção de estratégia de custo efetivo para prevenir e controlar essas afecções.

Levando em conta que o presente estudo permitiu uma primeira aproximação da realidade da mortalidade de mulheres com idade igual e superior a 50 anos, por câncer de mama, em nível populacional, o que se obteve foi um mapeamento inicial, que sugere a necessidade de outros estudos específicos e mais 
aprofundados, sobretudo nos grupos etários que, neste estudo, apresentaram maiores coeficientes de mortalidade por esssa neoplasia e que, parecem divergir de resultados de outros estudos, internacionalmente reconhecidos. Nesta linha, propõe-se que mulheres acima de 50 anos sejam assistidas e agrupadas em inúmeras coortes por idade. O planejamento em coorte pode se concentrar nas necessidades e problemas prioritários identificados por pesquisas ou dados disponíveis, com o cuidado para se considerarem as diferenças entre coortes femininas urbanas e rurais.

Considera-se importante promover a participação da comunidade no cuidado à saúde e serviços sociais para mulheres deste segmento etário; disseminar os conceitos de prevenção de doenças crônicas através dos meios de comunicação de massa; encorajar o envolvimento das mulheres acima de 50 anos para se responsabilizarem em se tornarem as principais promotoras de sua própria saúde; treinar os profissionais de saúde a respeito dos problemas das mulheres desta faixa etária e no provimento de informações, de modo a promover e estimular, na comunidade, atitudes, convicções e práticas apropriadas.

A magnitude do problema enfatiza a necessidade de se encontrar os possíveis fatores prognósticos, o que pode proporcionar melhor seleção de casos, influenciando na decisão e conduta terapêutica correta e apropriada.

É necessário que sejam realizados estudos de mortalidade, procurando sempre estabelecer distintamente a situação sócio-econômica e sanitária da população e empreender pesquisas para identificar necessidades específicas para uma variedade de grupos de idades, e não somente deste segmento etário, de mulheres acima de 50 anos. 
Ressalta-se que a detecção de câncer de mama por screening em mulher assintomática na menopausa apresenta a possibilidade de mudar a história natural da doença e reduzir a mortalidade por câncer de mama.

\section{CONCLUSÃO}

Ao descrever a evolução das taxas de mortalidade por câncer de mama em mulheres com idade igual e superior a 50 anos, no Estado de São Paulo, nos diferentes triênios de 1979-1997, concluímos que:

- De um modo geral, houve expressivo aumento ( $116,3 \%)$ do número desses óbitos, do primeiro para o quarto triênio do período estudado;

- Para o conjunto da faixa etária considerada ( 50 anos e mais) evidenciou-se o aumento das taxas de mortalidade por câncer de mama à medida que aumenta a idade. Para esse conjunto etário constatou-se variação do risco de morte, por câncer de mama, entre o primeiro e o quarto triênio ( $30,01 \%)$;

- $\mathrm{O}$ aumento do conjunto, entretanto, não significou a contribuição uniforme de todos os grupos, pelo contrário, constataram-se oscilações entre eles;

- Quanto ao percentual de óbitos, no grupo etário de 50-54 anos, constatou-se um decréscimo entre o primeiro e o últimos triênio estudado (5,86\%), seguido do grupo de 55-59 anos ( 4,14\%); no grupo 60-64 anos verificou-se aumento $(2,46 \%)$, diminuindo nas faixas etárias 65-69 anos e 70-74 anos, elevando-se a partir de 75 anos e mais ; 
- Maior aumento do valor dos coeficientes deu-se no grupo etário igual e acima de 75 anos, cujo coeficiente de mortalidade por câncer de mama, no último triênio, revela crescimento no período estudado ( 47,65 \%);

- Nos triênios estudados, constatou-se aumento do número de óbitos, em todas as regiões do Estado de São Paulo. A região que apresentou maior número de óbitos por câncer de mama de mulheres com idade igual e superior a 50 anos foi a Região Metropolitana (56,57\%);

- O percentual de óbitos por câncer de mama de mulheres na faixa etária e período estudados diminuiu no decorrer dos triênios na região Metropolitana, enquanto se observou aumento no Interior, porém o coeficiente de mortalidade por câncer de mama de mulheres na faixa etária de 50 anos e mais, no período em estudo, aumentou em ambas as regiões estudadas, ao longo dos triênios;

- A taxa bruta de mortalidade por câncer de mama, nos triênios de 19791981 e 1995- 1997, aumentou tanto na Região Metropolitana como no Interior; nos demais triênios, constatou-se oscilação;

- As taxas de mortalidade específicas por grupos etários, calculadas para os quatro triênios, evidenciaram que o risco de morrer por câncer de mama não aumentou continuamente com a idade, oscilando entre os grupos etários em mulheres com idade de 50 anos e mais, para o Estado de São Paulo, isto é, o risco variou entre os grupos etários durante o período estudado. 


\section{REFERÊNCIAS}

Abreu MAL. A mulher climatérica: passado, presente, futuro. Femina 1999 julho; 27(6).

Aldrighi JM. Anticoncepção no climatério. Femina 1992; 20(4): 274-91.

$7 \mathrm{u}$

Aldrighi JM. Balanço/risco/benefício da terapêutica de reposição hormonal: direção para o futuro. Rev Soc Cardiol Estado de São Paulo 1996; 6: 734.

Aldrighi JM, Araújo SDT, Alecrim I. História natural da osteoporose na mulher no climatério. Revista Brasileira de Medicina 1999; 56(Edição especial Osteoporose): 21-26.

American Cancer Society. Cancer facts \& figures. New York; 1996.

Audet-Lepointre P. Pitfalls in breast cancer screening: the female breast. In: Proceedings of the International Seminar on Gynecological Problems of the Breast. Roma; 1996. p. 21-26.

Austoker J. Screening and self-examination for breast cancer. British Medical Journal 1994; 309(6948): 168-74.

Baker RH. Breast cancer demonstration project: 5 years summary report. Cancer Journal for Clinican CA 1992; 32: 194-225. 
Baquet CR, Commiskey P. Socioeconomic factors and breast carcinoma in multicultural women. Cancer 2000 mar 1; 88(5 Suppl): 1.256-64

Baracat E. Estudo da atividade hormonal de mulheres tratadas com tamoxifeno no menacme. Rev Bras Ginecol Obstet 1998; 20(9): 553-6.

Baracat F. Estudo histométrico, hormonal e enzimático em pacientes com displasia mamária, tratadas com diferentes medicamentos. São Paulo, 1990; 99 p. ilus. tab. [Tese de Doutoramento - Escola Paulista de Medicina].

Barros Alfredo Carlos SD, Pinotti, JA. Bases teóricas da carcinogênese mamária. Rev Ginecol Obstet 1994; 5(2): 86-96.

Basinski ASH. The Canadian national breast cancer screening study: opportunity for a rethink. Canadian Medical Association Journal 1992; 147(10): 1431-4.

Boice Jr. JD, Morsan RR. Breast cancer in women after repeated fluoroscopic examinations of the chest. J Natl Cancer Inst 1977; 59: 823.

Boring CC, Squires TS, Tong T, Montgomery S. Cancer statistics. Cancer Journal for Clinican CA 1994; 44: 7-26.

Bower JE, Ganz PA, Desmond KA, Rowland JH, Meyerowitz BR, Belin TR. Fatigue in breast cancer survivors: occurrence, correlates, and impact on quality of life. J Clin Oncol 2000; 18(4): 743-53.

Brett AS. Breast cancer surveillance guidelines. J Clin Oncol 1999; 17: 1.080.

Caldeira JRF, Budin RMA. Aspectos epidemiológicos do câncer de mama em Jau/SP e alta incidência de casos avançados em mulheres idosas. Rev Bras Cancerol 1995; 41(1): 15-17. 
Carvalho FM. Bases biológicas do carcinogênese mamaria: papel dos esteróides. Rev Ginecol Obstet 1992; 3(4): 192-200.

Carvalho FM, Pinotti JA. The role of pathologist during surgery: non-palpable lesions and safety ressenctions in quadrantectomy. Rev Ginecol Obstet 1994; 5: 142-9.

Carvalho FM. et al. Pathological management of non palpable breast lesions. Rev Ginecol Obstet 1997; 8 (2): 64-71.

Chung M, Chang HR, Bland KI, Wanebo HJ. Young women with breast cancer have a poorer prognosis than older women. Cancer Journal for Clinican CA 1996; 77: 97 103.

Claudio DM, Marins JM. Cálculo numérico computacional. São Paulo: Atlas; 1989.

Collaborative Group on Hormonal Factors in Breast Cancer. Breast cancer and hormone replacement theraphy: collaborative reanalysis of data from 51 epidemiologic studies of 52,705 women with breast cancer and 104,4111 womem without breast cancer. Lancet 1997; 350: 1.047-59.

Colditz GA, Egan KM, Stampfer MJ. Hormone replacement therapy and risk of breast cancer: results from epidemiologic studies. Am J Obstet Gynecol 1993; 168(5):1.473-80.

Colditz GA, Hankinson SE et al. The use of estrogens and progestins and risk of breast cancer in postmenopausal women. N Engl J Med 1995; 332: 1.589-98.

Cooper RA. Mamograph. Clin Obstet Gynecol 1994: 32: 768-80. 
DATASUS - TABNET-CID - 10. Disponível em

http://datasus.asude.gov.br/cgi/tabcgi.exe/aim/dybr.def [1999 mar 29].

De Luca LA; Laurival A, Schimitt FC, Zambotti RP; De Luca HM; Traiman P. Recentes aquisições em mastologia. Rev Bras Mastologia 1998; 8(3): 154-56.

Dignam JJ. Differences in breast cancer prognosis among African-American and Caucasian women. CA Cancer J Clin 2000 Jan-Feb; 50(1):50-64.

Di Saia PJ, Grosen EA, Odicimo F et al. Replacement therapy for breast cancer survivors. Cancer Journal for Clinican CA 1995; 76: 2.075-8.

Doll R, Peto R. The causes of cancer: quantitative estimatives of avoidable riscks of cancer in USA today. Journal National Cancer Institute 1981; 166: 1.193-308.

Elledge RM. Epidemiology of breast cancer. J Natl Cancer Inst 1993; 86: 705-712.

Engel J, Baumert J, Holzel D. Early detection of breast cancer in Germany. Time to deal with the problem. Article in German. Radiologe 2000 fev; 40(2): 177-83.

Fardo MG. Câncer de próstata: mortalidade entre os residentes no Estado do Rio Grande do Sul no período de 1970 a 1992. São Paulo; 1999. [Dissertação de Mestrado - Departamento de Epidemiologia da Faculdade de Saúde Pública da Universidade de São Paulo].

Falzoni R. Câncer da mama: história natural e anatomia patológica. In: Halbe H. Tratado de ginecologia. 3. ed. São Paulo: Roca; 2000. v. 3, cap. 182, p. 2.027-41.

Feig SA. Decreased breast cancer mortality throug mamographic screening: results of clinical trial. Radiology 1998; 167:659-65. 
Finoth MCCF, Freitas Jr R. A importância da mamografia no climatério. Femina 1998; 26(6): 487-90.

Forbes JF. The incidence of breast cancer. The global burden. Public health considerations. Seminars in Oncology 1997; 24(1): S, 20-S-2 35.

Freitas F. Medicina por evidências e TRH. Reprod Clin 1998; 13(4): 203-4.

Freitas Jr. R, Baêta LF, Aires NM, Paulinelli RR, Finorri MCF, Silveira MT. Auto exame das mamas entre estudantes de medicina. RGBO 1999; 21(5).

Fundação IBGE - Instituto Brasileiro de Geografia e Estatística. Censo demográfico - São Paulo,1973, 1983, 1993, 1997 e1998.

Fundação IBGE - Instituto Brasileiro de Geografia e Estatística. Contagem nacional da população. On line 1996. Disponível “on line” http:||www.sidra.ibge.gov.br/

Gail MH, Benichou J. Validation studies on a model for breast cancer risk. J Natl Cancer Inst 1994; 86(8): 573-5.

Garber JE. Management of the high-risk and the cooncerned patient. In: Harris JR, Lippman ME, Marrow M et al. Diseases of breast. Philadelphia: Lippincott-Raven Publishers 1996; p. 323-34.

Goes Jr. JS. Câncer de mama: rastreamento, detecção e diagnóstico. In: Halbe H. Tratado de ginecologia. 2. ed. São Paulo: Roca; 1994. p. 1.711-14.

Gorsky RD, Koplan JP, Peterson HB, Tracker SB. Relative risk and benefits of longterm estrogen replacement therapy: a decision analysis. Obstet Gynecol 1994; 83:1616. 
Gotlieb, SLD. Mortalidade diferencial por causas - São Paulo 1970. São Paulo; 1977. [Tese de doutorado - Faculdade de Saúde Pública - USP].

Gotzsche PC, Olsen O. Is screening for breast cancer with mammography justifiable? Lancet 2000; 355: 129-34.

Greenbaum, L. That's what it is. Lancet, 2000; 355: 745-46.

Greenlee RT, Murray T, Bolden S, Wingo PA. Cancer statistics 2000. CA Cancer J Clin 2000 jan./fev.; 50(1): 7-33.

Grodstein F, Stampfer MJ, Colditz GA, Willett WC, Manson JE, Joffe M, Rosner B, Fuchs C, Hankinson SE, Hunter DJ, Hennekens CH, Speizer FE. Postmenopausal hormone therapy and mortality. N. Engl. J. Med. 1998; 336: 1769-1775.

Halbe HW. Tratado de ginecologia. São Paulo: Roca; 1992.

Halbe HW et al. Osteoporose: fatores de risco, hormônios ovarianos e prevenção. Revista Brasileira de Medicina 1999; 56(Edição especial Osteoporose): 4-10.

Harding $\mathrm{C}$ et al. Hormone replacement therapy and tumor grade in breast cancer. Prospective study in screening unit. BMJ 1996; 312: 1.646-47.

Hardy EE, Pinotti JA, Osis MJD, Faundes A. As variáveis reprodutivas e risco para doenças benignas da mama: estudo caso-controle. Rev Saúde Pública 1990; 24: 387393.

Heimann R, Hellman S. Clinical progression of brest Cancer malignant behavior: what to expect and when to expect it. Journal Of Clinical Oncology. 2000; 18(3): 591-599. 
Henderson IC. Risk factors for breast cancer development. Cancer 71 1993; (6):2.127-40.

Hortobaggi GN. Epidemioly of breast cancer. CA Cancer J Clin 1995; (45): 199-226.

Hulka BS, Liu ET, Lininger RA. Steroid hormones and risk of breast cancer. Cancer 1994; 74: 1.111-24.

Instituto Nacional de Câncer (INCA). O problema do câncer no Brasil. 4. ed. Rio de Janeiro: 1997.

Katz, A. Câncer de mama. Revista Brasileira de Medicina 1997; 54 (Edição Especial): 53-65.

Kenemans P, Scheele F, Burger CW. Hormone replacement therapy and breast cancer morbidity, mortality and recurence. Eur J Obstet Gynecol Reprod Biol 1997; 71(2): 199-203.

Koning HJ. Assessment of nationwide cancer-screening programmes. Lancet 2000; 355: $80-81$

Kopans DB. The accuracy of mammographic interpretation. The New England Journal of Medicine 1994; 331(22): 1521-2.

Landis SH, Murray T, Bolden S, Wingo PA. Cancer statistics. CA Cancer J Clin 1998; 48(1): 7-29.

Laurenti, R. Causas múltiplas de morte. São Paulo; 1973 [Tese de Livre-Docência Faculdade de Saúde Pública - USP).

Laurenti R., Melo Jorge MHP, Lebrão ML, Gotlieb SLD. Estatísticas de saúde. 2. ed. São Paulo: Ed. Pedagógica e Universitária; 1987. 
Lester RG. The contribution of radiology to the diagnosis, management and care of breast cancer. Radiology 1984; 152: 1-10.

Lobo, R. Benefits and risks of estrogen replacemente therapy. Estrogen Replacement: The envolving role of alternative delivery systems. Americ J. Obstet. Gynecol 1995 Sept (Pt 2); 173(3): 982.

Martorelli Filho B. Câncer da mama: rastreamento, detecção e diagnóstico precoce. In: Halbe H. Tratado de ginecologia. 3. ed. São Paulo: Roca; 2000. v. 3, cap. 181, p. 2.023-26.

Mendonça HMS. Análise crítica dos métodos de triagem na detecção e diagnóstico de câncer de mama. São Paulo; 1995. [Dissertação de Mestrado - Faculdade de Saúde Pública da USP].

Michaelson JS, Kopans DB, Cady B. The breast carcinoma screening interval is important. American Cancer Society 2000; 88(6): 1.282-284.

Mickey RM, Durski J, Worden JK, Danigelis N/L. Breast cancer screening and associated factors for low-income african-american women. Preventive Medicine 1995; 24: 467-76.

Milan C, Nunes CE, Barcellos L, Santos TG, Frasson AL. Câncer de Mama: importância da avaliação genética. Rev Bras Mastol 1998; 8: 204-210.

Miller AB, Baines CJ, To T, Wall C et al. Canadian National Breast Screening Study 1. Breast cancer detection and death rates among women aged 40 to 49 years. Can Med Assoc F 1992; 147: 1.459-76. 
Miller AB, Baines CJ, To T, Wall C et al. Canadian National Breast Screening Study 2. Breast cancer detection and death rates among women aged 50 to 59 years. Can Med Assoc F 1992; 147: 1.477-88.

Ministério da Saúde. Secretaria Nacional de Assistência à Saúde. Instituto Nacional de Câncer. Coordenação de Programas de Controle de Câncer. Estimativa da incidência e mortalidade por câncer no Brasil 1998. Rio de Janeiro. INCA/PROONCO; 1998.

Monsees B, Destonot JM, Gensel D. Light sacanning of non palpable breast lesion: reavaliation. Radiology 1998; 167: 352-360.

Morkovits M. Breast cancer screening: all's well that well or much and about nothing? Am J Roentgenol 1988; 151: 659-665.

Murphy Gerald et al. Text book of clinical oncology. Washington, DC: American Cancer Society; 1995.

National Cancer Institute. United States. PDQ - Detection \& Prevention - Health Professionals. 1998. http://cancernet.nei.nih.gov/clinpdq/creening for breast cancer.

Newcomb PA, Olsen SJ, Roberts FD, Storer BE, Love RR. Assessing breast self examination. Preventive Medicine 1995; 24(3): 255-8.

Pinotti JA. Detecção e controle do câncer mamário. In: Compêndio de mastologia. São Paulo: Manole; 1991. p. 282-96.

Pinotti JA, Teixeira LC. Câncer da mama: importância, epidemiologia e fatores de risco. In: Halbe H. Tratado de ginecologia. 3. ed. São Paulo: Roca; 2000. v. 3, cap. 180 , p. 2.019-22. 
Quella S, Loprinzi CL, Barton D et al. Evaluation of soy phytoestrogens for treatment of hot flashes in breast cancer survivors: an NCCTG trial. American Society of Clinical Oncology $35^{\text {th }}$ Annual Metting. Atlanta; 1999.

Quinn M, Allen E, United Kingdom Association of Cancer Registries. Changes in incidence of and mortality from breast cancer in England and Wales since introduction of screening. British Medical Journal 1995; 311(7017): 1.391-5.

Reynolds T. Declining breast cancer mortality: what's behind it? J. Natl. Cancer Inst 1999: 91(9): 750-3.

Rodger A. Towards a higher standard of breast cancer care. The Medical Journal of Australia 1995; 163(8): 434.

Rouquayrol MZ, Kerr-Pontes LRS. A medida da saúde coletiva. In: Rouquayrol, MZ. Epidemiologia \& Saúde. 4. ed. Rio de Janeiro; Medsi; 1994. p. 23-76.

Scott M. Core-biopsy guiada por imagem na mama. Gineco-News Serviço Brasileiro de Informação Médica 1999; (2): 17-22. Disponível em http:/www.gineconews.org

Seidman H, Geib S, Silversberg J. Surgical experience in the breast cancer demonstration project. CA Cancer J Clin 1987; 37: 258-61.

Schairer C, Gail M, Byrne C, Rosenberg PS, Sturgeon SR, Brinton LA, Hoover RN. Estrogen replacement theraphy and breast cancer survival in large screening study. $\mathrm{J}$ Natl Cancer Inst 1999 fev 3; 91(3): 264-70.

Shapiro S, Strax P, Venel L, Venet W. Periodic screening of breast cancer: the Health Insurance Plan Project and its sequelae (1963-1986). Baltimore: The John Hopkins University Press; 1998. 
Silva OE, Zurrida S. Cancer de mama: um guia para médicos. São Paulo: Atlântica, 2000.

Skinner CS, Strecher VJ, Hospers H. Physicians recommendations for mammography: do tailored messages make a difference? American Journal of Public Health, 1994; 84(1): 439.

Souen JS. Cânceres de mama não paupáveis: diagnóstico e conduta. Experiência pessoal. Rev Bras Ginecol Obstet 1996; 18: 507-510.

Souen JS (a). Detecção precoce do câncer de mama. Femina 1998; 26(7): 609-10.

Souen JS (b). Mamografia: acertos e desacertos. Femina 1998; 26(7): 537.

Speroff L. A mama. In: Endocrinologia ginecológica clínica e infertilidade. 5. ed. São Paulo: Manole; 1995. cap. 9, p. 347-56.

Spratt JS, Donegan WL. Cancer of the breast. Philadelphia: WB Saunders; 1995.

Spritzer PM, Reis FM. Reposição hormonal no climatério: princípios terapêuticos embasados em evidências. Reprod Clim 1998; 13(1): 32-41.

Starreveld A.A. The Canadian National Breast Screening Study: a clinician's perspective. Canadian Medical Association Journal 1992;147(10): 1437-9.

Steinberg KK, Tracher SB, Smith SJ et al. A meta-analysis of the effect of estrogen replacement therapy on the risk of breast cancer. JAMA 1991; 265:1985-90.

Stocks P. The epidemiology of cancer of breast. In: Schottenfeld, I, Fracemini JF, Orgs. Cancer epidemiology and prevention. Philadelphia: WB Saunders; 1982. 
Stomper PC et al. Mamographic changes associated with postmenopausal hormone replacement therapy: a longitudinal study. Radiology 1990; 174: 487-90.

Sutton S, Saidi G, Bickler G, Hunter J. Does routine screening for a breast cancer raise anxiety? Results from a three prospective study. England. Journal of Epidemiology Community Health 1995; 49(4): 413-8.

Tabar L, Dean PB, Duffy SW, Chen HH. A new era in the diagnosis of breast cancer. Surg Oncol Clin N Am 2000 abr; 9(2): 233-77

Thomas DB, Gao DL, Self SG et al. Randomized trial of breast self examination in Shangai: methodology and preliminary results. J Natl Cancer Inst 1997; 89(5): 355-65.

UK Trial. Breast cancer: a guide for sellows. Lancet 1988; 2: 411-6.

United States. National services by women ages: 65 years enrolled in Medicare United States, 1991-1993. Morb Mortal Weekly Rep 1995; 44: 777-81.

Xavier NL, Xavier MC. Hormônios e gênese do câncer de mama: atualização. J Bras Ginecol 1996; 106(6): 189-196.

World Health Organization. Cancer incidence in five continents. IARC Scientific Publ 1992; 6.

World Health Organization. International Agency for research on cancer. Colleman MP, Esteve J, Damiecki P, Arslan A, Renard H. Trends in cancer incidence and mortality, 1993. 
De acordo com:

Universidade de São Paulo. Faculdade de Saúde Pública. Biblioteca/CIR. Guia de apresentação de teses. Grupo de Trabalho: Angela Maria Belloni Cueca, Daisy Pires Noronha, Maria Lúcia Evangelista de Faria Ferraz, Maria Teresinha Dias de Andrade. São Paulo: A Biblioteca; 1998. 